\title{
Linker Redox Mediated Control of Morphology and Properties in Sem- iconducting Iron-Semiquinoid Coordination Polymers
}

\author{
Lei Wang, ${ }^{1}$ Robert J. Papoular, ${ }^{2}$ Noah E. Horwitz, ${ }^{1}$ Jiaze Xie, ${ }^{1}$ Norman Zhao, ${ }^{1}$ Baorui Cheng, ${ }^{1}$ \\ Tengzhou Ma, ${ }^{3}$ Alexander S. Filatov, ${ }^{1}$ and John S. Anderson*,1 \\ ${ }^{1}$ Department of Chemistry, University of Chicago, Chicago, Illinois 60637, United States \\ 2IRAMIS, Leon Brillouin Laboratory, CEA-Saclay, F-91191 Gif-sur-Yvette, France \\ ${ }^{3}$ Pritzker School of Molecular Engineering, University of Chicago, Chicago, IL 60637, United States
}

\begin{abstract}
The emergence of conductive 2D, and less commonly 3D, coordination polymers (CPs) and metal-organic frameworks (MOFs) promises novel applications in chemical sensing, energy storage, optoelectronics, thermoelectrics, and spintronics. While classic CPs and MOFs now have relatively sophisticated synthetic parameters to control morphology, crystallinity, and phase purity, similar parameters are not thoroughly understood for electronically more complex materials. In particular, many linkers used in conducting CPs have multiple accessible redox states and the relationship between starting linker oxidation state and final material structure and properties is not well understood. Here we report a new 3D semiconducting coordination polymer, $\mathbf{F e}_{5}\left(\mathbf{C}_{6} \mathbf{O}_{6}\right)_{3}$, which is composed of hexagonal $\mathrm{Fe}_{2}\left(\mathrm{C}_{6} \mathrm{O}_{6}\right)_{3}$ layers which are bridged by additional $\mathrm{Fe}$ ions. This material, which is a fusion of $2 \mathrm{D} \mathrm{Fe}$-semiquinoid materials and recently reported $3 \mathrm{D}$ cubic $\mathbf{F e}_{\mathbf{x}}\left(\mathbf{C}_{\mathbf{6}} \mathbf{O}_{\mathbf{6}}\right)_{\mathbf{y}}$ materials, is obtained by using a different initial redox-state of the $\mathrm{C}_{6} \mathrm{O}_{6}$ linker. The material displays high electrical conductivity $(0.02$ $\left.\mathrm{S} \mathrm{cm}^{-1}\right)$, broad electronic transitions in the visible to middle-infrared region, promising thermoelectric behavior $\left(S^{2} \sigma=4.2 \times 10^{-}\right.$ ${ }^{9} \mathrm{~W} \mathrm{~m}^{-1} \mathrm{~K}^{-2}$ ), and strong antiferromagnetic interactions even at room temperature. The unique structure and properties of this material illustrates that controlling the oxidation states of redox-active components in conducting CPs can be a "presynthetic" strategy to carefully tune material topologies, properties, and functionalities in contrast to more commonly encountered post-synthetic modifications.
\end{abstract}

\section{Introduction}

Introducing novel bulk electronic properties such as charge mobility or electrical conductivity into coordination polymers (CPs) and metal-organic frameworks (MOFs) has been an area of very active research in recent years. ${ }^{1}$ These features, while interesting in their own right, are even more appealing when combined with the tunable topologies and structures that are hallmarks of CPs and MOFs. ${ }^{2}$ Thus, this emerging class of multifunctional materials has found many novel applications in chemical sensing, ${ }^{3}$ electrochemical energy storage, ${ }^{4}$ optoelectronics, ${ }^{5}$ thermoelectrics, ${ }^{6}$ magnetism and spintronics. ${ }^{7}$ While the exploration of promising functionalities and applications in these materials has been a major focus, for instance in using sophisticated physical characterization methods ${ }^{8}$ and theoretical calculations ${ }^{9}$ to study carrier transport mechanisms, the exploration of the synthetic space ${ }^{8 \mathrm{~d}, 10}$ of these new electronic materials is still nascent. This is particularly true when contrasted to the rich morphological, structural, defect, and phase space of more traditional MOF candidates which can largely be controlled by choice of synthetic conditions, additives, or linker morphology. ${ }^{11}$

When considering synthetic variables for electronically complex CPs and MOFs, the redox-states of the metal and linker components are a critical factor. ${ }^{12}$ For example, Sun et al. measured the electrical conductivity and activation energy for twenty different MOFs in four distinct structural families. They found that Fe-based MOFs displayed significantly higher conductivities and smaller charge activation energies due to in-situ oxidation to form Fe(II/III) mixed valency in contrast to the other metals which maintain divalent oxidation states. ${ }^{13}$ Similar examples can be seen for linkers. Quinone-based linkers are prototypical redox-active motifs and numerous examples of new conducting or magnetic $\mathrm{CPs} / \mathrm{MOFs}$ have been reported using linkers of the form $\left(\mathrm{C}_{6} \mathrm{O}_{4} \mathrm{X}_{2}\right)\left(\mathrm{X}=\mathrm{H}, \mathrm{F}, \mathrm{Cl}, \mathrm{Br}, \mathrm{I}, \mathrm{NO}_{2}, \mathrm{CN}\right) .{ }^{14}$ Despite the importance of the final linker redox-state for materials structure and properties, leveraging different linker-redox states as a synthetic strategy, such as using different quinone redox-isomers in syntheses, has not been thoroughly investigated.

Taken to the limit of monocyclic quinones, hexahydroxybenzene (HHB) or tetrahydroxy-1,4-quinone (THQ), has the most accessible redox-isomers and several possible radical based intermediates (Figure 1). ${ }^{10,15}$ As such, this linker is an extremely attractive target for incorporation into new materials, but also offers unique challenges in predicting or controlling the redox-state of resulting MOFs. The first 2D semiconducting MOF featuring this motif, $\mathrm{Cu}-\mathrm{HHB}$

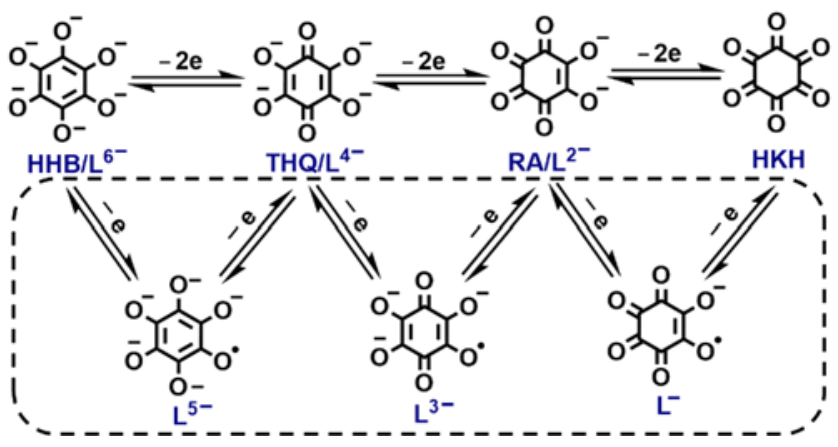

Figure 1. Multiple accessible oxidation states (top) and possible intermediates (in dashed box) of $\mathrm{C}_{6} \mathrm{O}_{6}$. 
$\left[\mathrm{Cu}_{3}\left(\mathrm{C}_{6} \mathrm{O}_{6}\right)_{2}\right]$, was synthesized in 2018 by reacting $\mathrm{Cu}(\mathrm{II})$ with either HHB or THQ. ${ }^{10 e}$ This material displays good performance in lithium-ion battery and photoconductivity applications as illustrated by later reports, ${ }^{4 \mathrm{e}, 8 \mathrm{c}}$ but an interesting observation is that the same structure is formed regardless of the linker precursor oxidation state. Switching from $\mathrm{Cu}(\mathrm{II})$ to a more easily oxidized Fe(II) ion results in two novel 3D conducting MOFs, namely $\mathbf{F e}_{12}\left(\mathbf{C}_{6} \mathbf{O}_{6}\right)_{6}$ and $\mathbf{F e}_{\mathbf{8}}\left(\mathbf{C}_{6} \mathbf{O}_{6}\right)_{6 .}{ }^{16}$ Although these two materials have generally cubic unit cells, the connections between metals and linkers as well as the final oxidation states of the linkers are different (Figure 2A top), likely due to the subtle differences in reaction conditions. Both of these examples provide concrete illustrations of how different materials can result from common or closely related precursors due to different synthetic protocols. This is particularly true in metal-semiquinoid based materials as spontaneous redox chemistry likely plays an important role upon material formation and growth.

We were intrigued by the multiple accessible precursor redox-states of $\mathrm{C}_{6} \mathrm{O}_{6}$ linkers in this family of materials, particularly in the context of varying material structure and properties through different initial linker redox states. Herein, we present the synthesis of a new 3D semiconducting $\mathrm{CP}, \mathbf{F e}_{5}\left(\mathbf{C}_{6} \mathbf{O}_{6}\right)_{3}$, which is generated by reacting $\mathrm{Fe}(\mathrm{II})$ with the most reduced linker precursor HHB instead of THQ. In contrast to the $\mathrm{Cu}$ systems mentioned above, the use of a different redox-state of the linker results in a dramatically different structure. Like most other quinone-

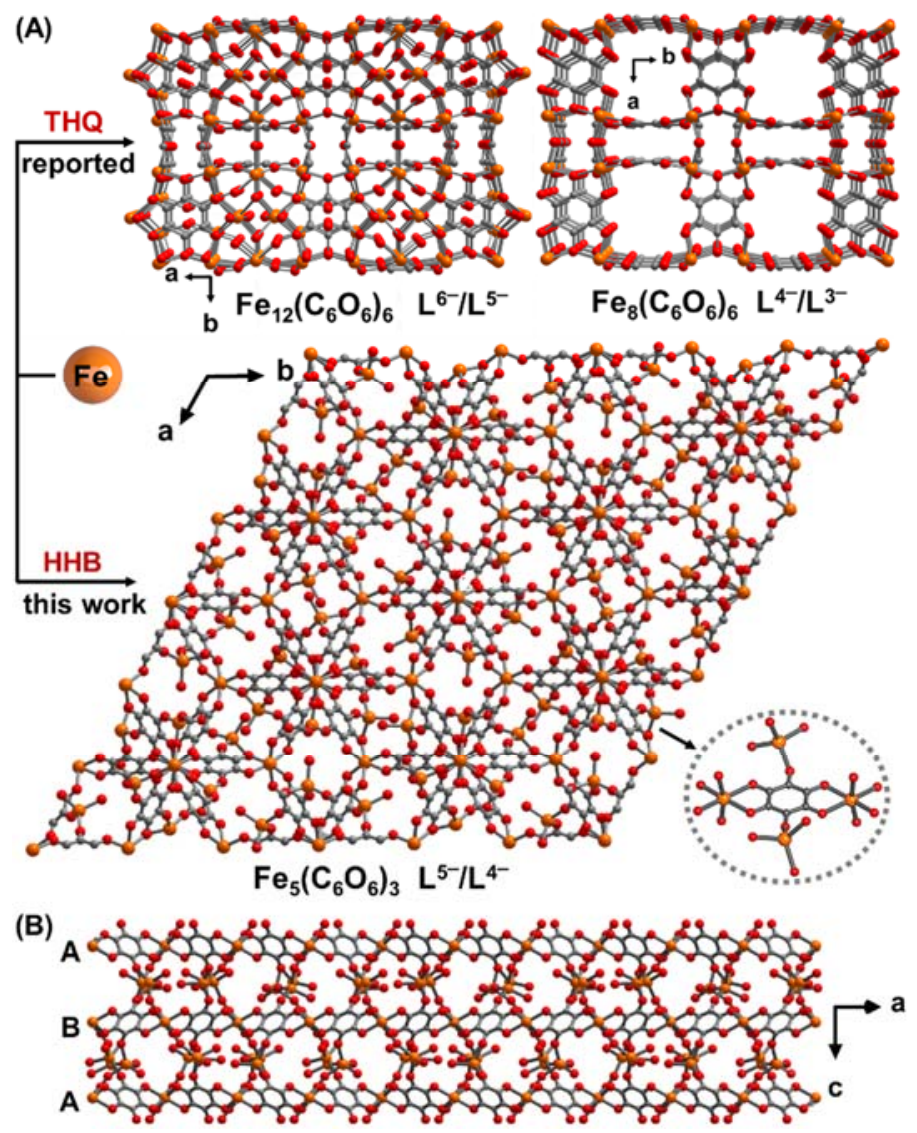

based coordination polymers of this type, $\mathbf{F e}_{\mathbf{5}}\left(\mathbf{C}_{6} \mathbf{O}_{6}\right)_{3}$ consists of hexagonal layers but with a staggered $A B$ stacking. Moreover, these layers are further bridged by axial Fe centers through $\mathrm{Fe}-\mathrm{O}$ bonds to generate a $3 \mathrm{D}$ material (Figure $2 \mathrm{~A}$ bottom). This novel topology is reminiscent of retrofitting modifications used in carboxylate-based MOFs to affect material properties, ${ }^{17}$ as well as proposed approaches to promote delocalization of charge by extending into three dimensions. ${ }^{9 \mathrm{~d}}$ The optical absorption, conductivity, Seebeck coefficient, and magnetic susceptibility of $\mathbf{F e}_{\mathbf{5}}\left(\mathbf{C}_{\mathbf{6}} \mathbf{O}_{\mathbf{6}}\right)_{\mathbf{3}}$ have been explored, revealing redox-state and structurally dependent trends. The isolation of this new material in the $\mathbf{F e}_{\mathbf{x}}\left(\mathbf{C}_{6} \mathbf{O}_{6}\right)_{\mathbf{y}}$ family demonstrates the rich morphological, structural, and phase space available to these electronically interesting CPs. Furthermore, our studies demonstrate that, in contrast to post-synthetic modifications, pre-synthetically controlling the redox-states of components in conductive or magnetic coordination polymers is an important parameter for encoding properties and functionalities.

\section{Results and Discussion}

Synthesis and structure

$\mathbf{F e}_{5}\left(\mathbf{C}_{6} \mathbf{O}_{6}\right)_{3}$ was prepared by reacting anhydrous $\mathrm{FeCl}_{2}$ with $\mathrm{HHB}$ in dimethylformamide (DMF) at $100^{\circ} \mathrm{C}$ for three days under an inert atmosphere. These synthetic conditions are similar to those reported for $\mathbf{F e}_{\mathbf{1 2}}\left(\mathbf{C}_{6} \mathbf{O}_{6}\right)_{6}$ and $\mathbf{F e}_{\mathbf{8}}\left(\mathbf{C}_{6} \mathbf{O}_{6}\right)_{6}$ but with slight modifications to maintain the integrity of the HHB linker. Reaction condition screening

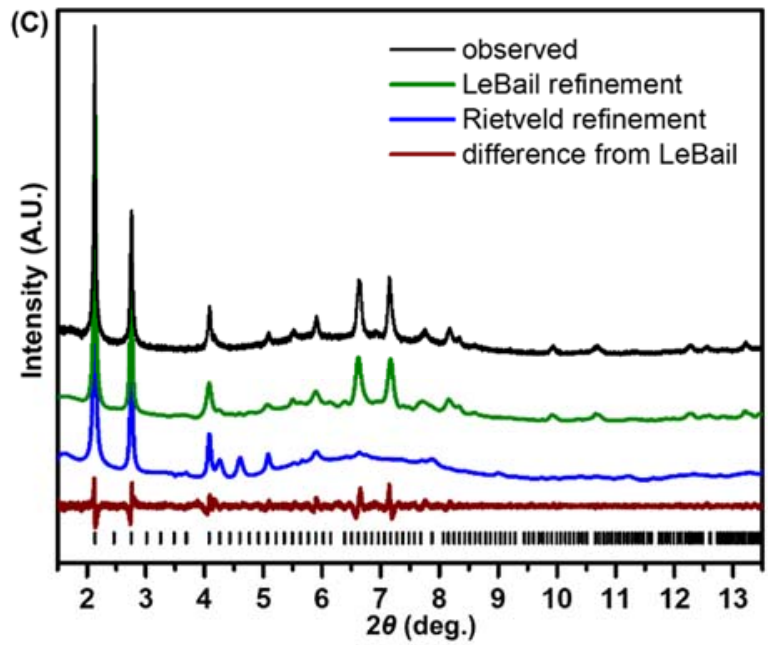

(D)

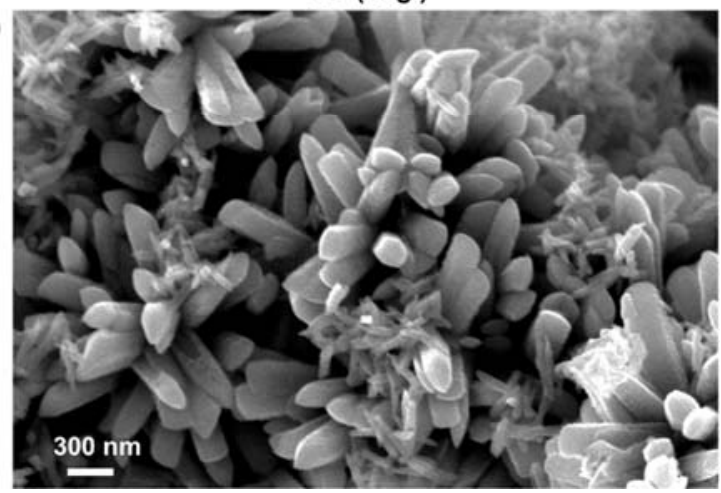

Figure 2. (A) Schematic illustration of the previously reported 3D materials $\mathbf{F e}_{\mathbf{1 2}}\left(\mathbf{C}_{\mathbf{6}} \mathbf{O}_{6}\right)_{6}$, $\mathbf{F e}_{\mathbf{8}}\left(\mathbf{C}_{\mathbf{6}} \mathbf{O}_{6}\right)_{\mathbf{6}}$ and the $\mathbf{F e}_{5}\left(\mathbf{C}_{\mathbf{6}} \mathbf{O}_{6}\right)_{\mathbf{3}}$ material reported here. (B) Orientation of neighboring layers in $\mathbf{F e}_{\mathbf{5}}\left(\mathbf{C}_{\mathbf{6}} \mathbf{O}_{6}\right)_{3}$. Orange: Fe, red: O, grey: C; coordinated solvent molecules are omitted for clarity. (C) Comparison of the synchrotron X-ray powder diffraction data (295 K, $\lambda=0.458093 \AA$ ) and calculated (LeBail and Rietveld) patterns in $P_{63}$. (D) SEM image of $\mathbf{F e}_{5}\left(\mathbf{C}_{6} \mathbf{O}_{6}\right)_{3}$ powder. 
shows that adding base (triethylamine, dimethylamine) or other polar solvents (water, methanol, diethylene glycol) decreases the crystallinity of the resulting material. X-ray powder diffraction (XRPD) data of the product indicated formation of a crystalline material (Figure 2C, Figure S2), and the pattern can be indexed in a primitive hexagonal unit cell $a=b=24.63 \AA, c=14.93 \AA, \alpha=\beta=90^{\circ}$, and $\gamma=120^{\circ}$. The LeBail fit shows that essentially all of the observed Bragg peaks can be accounted for by this unit cell and the $P 6_{3}$ space group (Figure S4-S5, see experimental section for a description of the structure solution).

The structure was solved by scripting the algebraic computations of the molecular fragments and the resulting framework layers with a python programming language that followed simulated annealing global optimizations. The final structure of $\mathbf{F e}_{5}\left(\mathbf{C}_{6} \mathbf{O}_{6}\right)_{3}$, as depicted in Figure 2A, shows that $40 \%$ of the Fe atoms are octahedrally coordinated with $\mathrm{C}_{6} \mathrm{O}_{6}$ units to form extended hexagonal layers. These hexagonal layers are reminiscent of similar layers in quinone-based materials and are significantly different from the pseudocubic structures observed for the $\mathbf{F e}_{12}\left(\mathbf{C}_{6} \mathbf{O}_{6}\right)_{6} / \mathbf{F e}_{8}\left(\mathbf{C}_{6} \mathbf{O}_{6}\right)_{6}$ materials previously reported. However, in $\mathbf{F e}_{\mathbf{5}}\left(\mathbf{C}_{\mathbf{6}} \mathbf{O}_{\mathbf{6}}\right)_{\mathbf{3}}$ the layers are packed in a staggered $\mathrm{ABAB}$ pattern and neighboring layers have a mirror-like orientation (Figure 2B). These 2D layers are further bridged by extra Fe atoms $(60 \%)$ which link them into a 3D structure similar to that found in layered lanthanide metal-organic frameworks. ${ }^{18}$ The coordination environment of these bridging Fe atoms is completed by solvent molecules, however, the positions of these solvents are unsurprisingly highly disordered, thus precluding a precise determination of their positions. The Rietveld refinement of the model lacking exact positions of solvent molecules shows a satisfactory agreement with the experimental pattern (a final $R_{\mathrm{p}}$ value is $12.2 \%$, Figure $2 \mathrm{C}$, Table S3).

Combustion and thermogravimetric analysis are consistent with this structural assignment with a formula of $\mathrm{Fe}_{5}\left(\mathrm{C}_{6} \mathrm{O}_{6}\right)_{3}\left(\mathrm{H}_{2} \mathrm{O}\right)_{3}\left(\mathrm{C}_{3} \mathrm{H}_{7} \mathrm{NO}\right)_{3}$ (Table S1 and Figure S11). Scanning electron microscopy (SEM) images show a hexagonal rod- or needle-like morphology which is also consistent with the structural assignment (Figure 2D). The size of the particles ranges from $200 \mathrm{~nm}$ to $1 \mu \mathrm{m}$ due to substantial interparticle growth. Furthermore, $\mathrm{N}_{2}$ uptake experiments suggest a type II isotherm and a measured BET surface area of $41.7 \mathrm{~m}^{2} / \mathrm{g}$ (Figure S12). Both results indicate a lack of porosity of the material as expected from the staggered $\mathrm{AB}$ packing and the existence of interlayer bridging $\mathrm{Fe}$ with coordinated solvent molecules.

This unusual structure is distinct from both 2D semiquinoid MOFs as well as the 3D materials derived from THQ. $\mathbf{F e}_{5}\left(\mathbf{C}_{6} \mathbf{O}_{6}\right)_{3}$ has two distinct coordination environments for Fe: octahedral intralayer and pseudotetrahedral interlayer. In $\mathbf{F e}_{12}\left(\mathbf{C}_{6} \mathbf{O}_{6}\right)_{6}$, the $\mathrm{O}$ atoms from each $\mathrm{C}_{6} \mathrm{O}_{6}$ linker all coordinate in an $\eta^{2}$-bridging manner such that each $\mathrm{Fe}$ atom is either connected with six 0 atoms from three perpendicular $\mathrm{C}_{6} \mathrm{O}_{6}$ linkers $(66 \%)$ or ligated by a combination of two $\mathrm{O}$ atoms from $\mathrm{C}_{6} \mathrm{O}_{6}$ linkers and four $\mathrm{O}$ atoms from solvent (33\%). In $\mathbf{F e}_{\mathbf{8}}\left(\mathbf{C}_{\mathbf{6}} \mathbf{O}_{\mathbf{6}}\right)_{6}$, all the $\mathrm{Fe}$ atoms are symmetrically coordinated to three perpendicular $\mathrm{C}_{6} \mathrm{O}_{6}$ units but the 0 can either be $\eta^{2}$ or solely coordinated to a single Fe center. In contrast, all of the 0 atoms in $\mathbf{F e}_{5}\left(\mathbf{C}_{6} \mathbf{O}_{6}\right)_{3}$ coordinate to
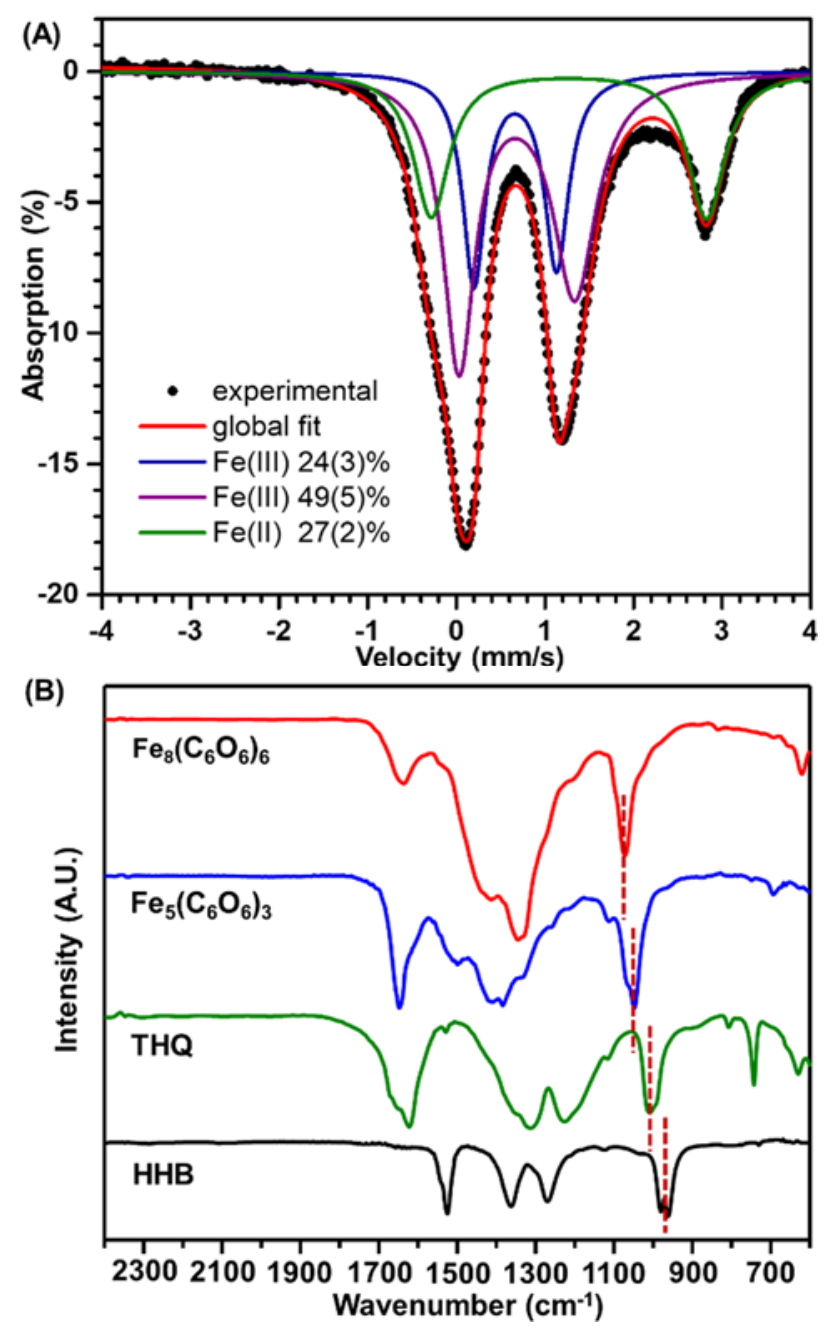

Figure 3. (A) ${ }^{57} \mathrm{Fe}$ Mössbauer spectrum recorded at $77 \mathrm{~K}$ and fitting results for three species. (B) FTIR spectrum of the HHB, THQ, $\mathbf{F e}_{5}\left(\mathbf{C}_{6} \mathbf{O}_{6}\right)_{3}$ and $\mathbf{F e}_{\mathbf{8}}\left(\mathbf{C}_{\mathbf{6}} \mathbf{O}_{6}\right)_{6}$ recorded in transmission mode (dashed red lines mark the $\mathrm{C}-\mathrm{O}$ stretching bands).

only one Fe atom. The unusual structure of $\mathbf{F e}_{5}\left(\mathbf{C}_{6} \mathbf{O}_{6}\right)_{3}$ suggests that it should also have unusual electronic and physical properties.

\section{Oxidation states of the components}

X-ray photoelectron spectroscopy (XPS) was initially used to probe the oxidation state of the $\mathrm{Fe}$ ions in $\mathbf{F e}_{5}\left(\mathbf{C}_{6} \mathbf{O}_{6}\right)_{3}$ (Figure S14). A broad Fe $2 p_{3 / 2}$ peak is observed which is centered around $710.5 \mathrm{eV}$. The position of this peak suggests a mixed valent material as compared with values in iron oxides $\left(\mathrm{FeO} \approx 709.5 \mathrm{eV}, \mathrm{Fe}_{2} \mathrm{O}_{3} \approx 711 \mathrm{eV}\right) .{ }^{19}$ Further corroboration of mixed valency is obtained from ${ }^{57} \mathrm{Fe}$ Mössbauer spectroscopy where three sets of signals are observed in the spectrum (Figure 3A and Figure S15). One of the Fe sites $(\sim 24 \%)$ has an isomer shift $(\delta)$ of $0.665(1)$ $\mathrm{mm} / \mathrm{s}$ and a quadrupole splitting $\left(\Delta E_{\mathrm{Q}}\right)$ of $0.933(7) \mathrm{mm} / \mathrm{s}$ while another $(\sim 49 \%)$ has a $\delta$ of $0.683(2) \mathrm{mm} / \mathrm{s}$ and a $\Delta E_{\mathrm{Q}}$ of $1.308(14) \mathrm{mm} / \mathrm{s}$. Both of these sets of parameters are consistent with an assignment of high-spin Fe(III) centers although the observed $\delta$ 's are slightly larger than those assigned to high spin Fe(III) centers in iron-semiquinoid complexes and CPs. ${ }^{14 b, 14 c, 20}$ For instance, the $\delta$ is $0.574(2) \mathrm{mm} / \mathrm{s}$ 
for the 3D $\left(\mathrm{NBu}_{4}\right)_{2}\left[\mathrm{Fe}_{2}(\mathrm{dhbq})_{3}\right]$ material. ${ }^{14 \mathrm{~b}}$ The larger isomer shift may be due to a decrease in electron density on the $\mathrm{Fe}(\mathrm{III})$ centers in our material. ${ }^{14 c}$ The third feature $(\sim 27 \%)$ has a $\delta$ of $1.269(3) \mathrm{mm} / \mathrm{s}$ and a $\Delta E_{\mathrm{Q}}$ of $3.105(4)$ $\mathrm{mm} / \mathrm{s}$ which distinctly assigns this site as a high-spin Fe(II) species. ${ }^{21}$ Digestion experiments show no evidence for the presence of $\mathrm{Me}_{2} \mathrm{NH}_{2}{ }^{+}$in the material for charge balance (Figure S13). Given the overall oxidation states of the Fe centers obtained from Mössbauer spectroscopy and the molecular formula, the oxidation state of the organic linkers is estimated to be -4.5 per $\mathrm{C}_{6} \mathrm{O}_{6}$ unit.

Corroborating evidence of the oxidation state of the linkers was obtained from Fourier-transform infrared (FTIR) spectroscopy. As shown in Figure 3B, after coordination a stretching band around $1000 \mathrm{~cm}^{-1}$ in $\mathbf{F e}_{\mathbf{5}}\left(\mathbf{C}_{\mathbf{6}} \mathbf{O}_{\mathbf{6}}\right)_{3}$, tentatively assigned to a $\mathrm{C}-\mathrm{O}$ vibration, shifts to a higher frequency compared to the free ligand HHB. This shift suggests a more oxidized linker in $\mathbf{F e}_{5}\left(\mathbf{C}_{6} \mathbf{O}_{6}\right)_{3}$ than in the starting ligand. A similar shift is also observed between THQ and Fe8( $\left.\mathbf{C}_{6} \mathbf{O}_{6}\right)_{6}$. In addition, comparison of the two Fe materials reveals a slightly lower $\mathrm{C}-\mathrm{O}$ stretching frequency in $\mathbf{F e}_{\mathbf{5}}\left(\mathbf{C}_{\mathbf{6}} \mathbf{O}_{6}\right)_{3}$ than in $\mathbf{F e}_{\mathbf{8}}\left(\mathbf{C}_{6} \mathbf{O}_{6}\right)_{6}$. This supports a more reduced linker oxidation state in the former material, as would be consistent with the formal oxidation state of roughly -4.5 which would arise from mixed valency between $\mathrm{L}^{5-} / \mathrm{L}^{4-}$ for the HHB linkers as indicated by Mössbauer analysis. In comparison, the calculated average charge from Mössbauer analysis is $\mathbf{- 5 . 4}$ and -3.6 per $\mathrm{C}_{6} \mathrm{O}_{6}$ unit in the related cubic materials $\mathbf{F e}_{12}\left(\mathbf{C}_{6} \mathbf{O}_{6}\right)_{6}$ and $\mathbf{F e}_{8}\left(\mathbf{C}_{6} \mathbf{O}_{6}\right)_{6}$, potentially suggesting a mixed valency of $\mathrm{L}^{6-} / \mathrm{L}^{5-}$ in and $\mathrm{L}^{4-} / \mathrm{L}^{3-}$ respectively. The significantly different formal linker oxidation states in these materials, in addition to their distinct structures, illustrates the rich composition space that is available for these conductive MOFs and also shows how using linker redox states can be a valuable tool to explore new phases of these materials.

\section{Electronic properties}

The electronic properties of $\mathbf{F e}_{5}\left(\mathbf{C}_{6} \mathbf{O}_{6}\right)_{3}$ were then explored with a variety of techniques. UV-vis-NIR diffuse reflectance spectroscopy shows four major absorption signals (Figure 4A, S16). The sharp peak centered at around 300 $\mathrm{nm}$, which is also seen in the free ligand, is assigned to a $\pi \rightarrow$ $\pi^{*}$ transition in the organic linkers. ${ }^{22}$ The shoulder-like peak, which is more obvious in the solution spectra of a suspension (Figure S16), at around $370 \mathrm{~nm}$ is tentatively assigned to an internal transition from the radical linkers $\left(\mathrm{L}^{5-}\right)$ although this transition occurs at around $470 \mathrm{~nm}$ in the chloranilate based radical ( $\left.\mathrm{CA}^{3-}\right)$ and the 2,5-dihydroxy-1,4benzoquinone based radical (DHBQ $\left.{ }^{3-}\right) .{ }^{23}$ The peak at around $560 \mathrm{~nm}$ in $\mathbf{F e}_{\mathbf{5}}\left(\mathbf{C}_{6} \mathbf{O}_{6}\right)_{3}$ is reasonably assigned as a ligand-tometal charge transfer band, which is similarly observed in a semiquinone-catecholate based mononuclear iron complex and iron semiquinoid-based MOFs. ${ }^{4 \mathrm{f}, 22}$

Most notably, $\mathbf{F e}_{\mathbf{5}}\left(\mathbf{C}_{\mathbf{6}} \mathbf{O}_{6}\right)_{3}$ displays a strong and broad absorption starting from $650 \mathrm{~nm}$ and tailing to $2700 \mathrm{~nm}$. This broad absorption is indicative of an intervalence charge transfer (IVCT) and can be classified as Class II/III according to the Robin-Day formalism. ${ }^{12 b}$ It is worthwhile to note that the first observation of Class II/III ligand-based mixedvalency in a MOF was in $\left(\mathrm{NBu}_{4}\right)_{2} \mathrm{Fe}_{2}(\mathrm{dhbq})_{3}$ with an IVCT transition band centered at around $1428 \mathrm{~nm}\left(v_{\max }=7000\right.$ $\left.\mathrm{cm}^{-1}\right){ }^{14 \mathrm{~b}}$ Later, several metal-semiquinoid frameworks have displayed Robin-Day Class II/III mixed-valency with broad absorbances in the mid-IR region extending to the near-IR region. ${ }^{14 \mathrm{e}}$ Even among this group, our material features a notably broad adsorption ranging from the visible to mid-IR region. The breadth of this feature may be attributed to dual mixed valency from both metal centers and organic linkers. An estimated band gap $\left(\mathrm{E}_{\mathrm{g}}\right)$ of $0.75 \mathrm{eV}$ is obtained from a Tauc plot with a direct band gap fitting (Figure $4 \mathrm{~A}$ inset) and is very similar to that observed in the two 3D $\mathbf{F e}_{12}\left(\mathbf{C}_{6} \mathbf{O}_{6}\right)_{6} / \mathbf{F e}_{8}\left(\mathbf{C}_{6} \mathbf{O}_{6}\right)_{6}$ materials supporting that all of these compounds feature mixed-valency.

The electrical conductivity of $\mathbf{F e}_{5}\left(\mathbf{C}_{6} \mathbf{O}_{6}\right)_{3}$ was measured as an average of $0.02 \pm 0.004 \mathrm{Scm}^{-1}$ on pressed pellets at room temperature using a two-probe method (Figure S17). This value is similar to other $3 \mathrm{D}$ conducting MOFs and slightly higher than $\mathbf{F e}_{\mathbf{8}}\left(\mathbf{C}_{\mathbf{6}} \mathbf{O}_{6}\right)_{\mathbf{6}}$ and $\mathbf{F e}_{\mathbf{1 2}}\left(\mathbf{C}_{6} \mathbf{O}_{6}\right)_{\mathbf{6}}$ despite the more anisotropic layered structure in $\mathbf{F e}_{5}\left(\mathbf{C}_{\mathbf{6}} \mathbf{O}_{6}\right)_{3}{ }^{1 \mathrm{~d}, 2 \mathrm{~d}}$
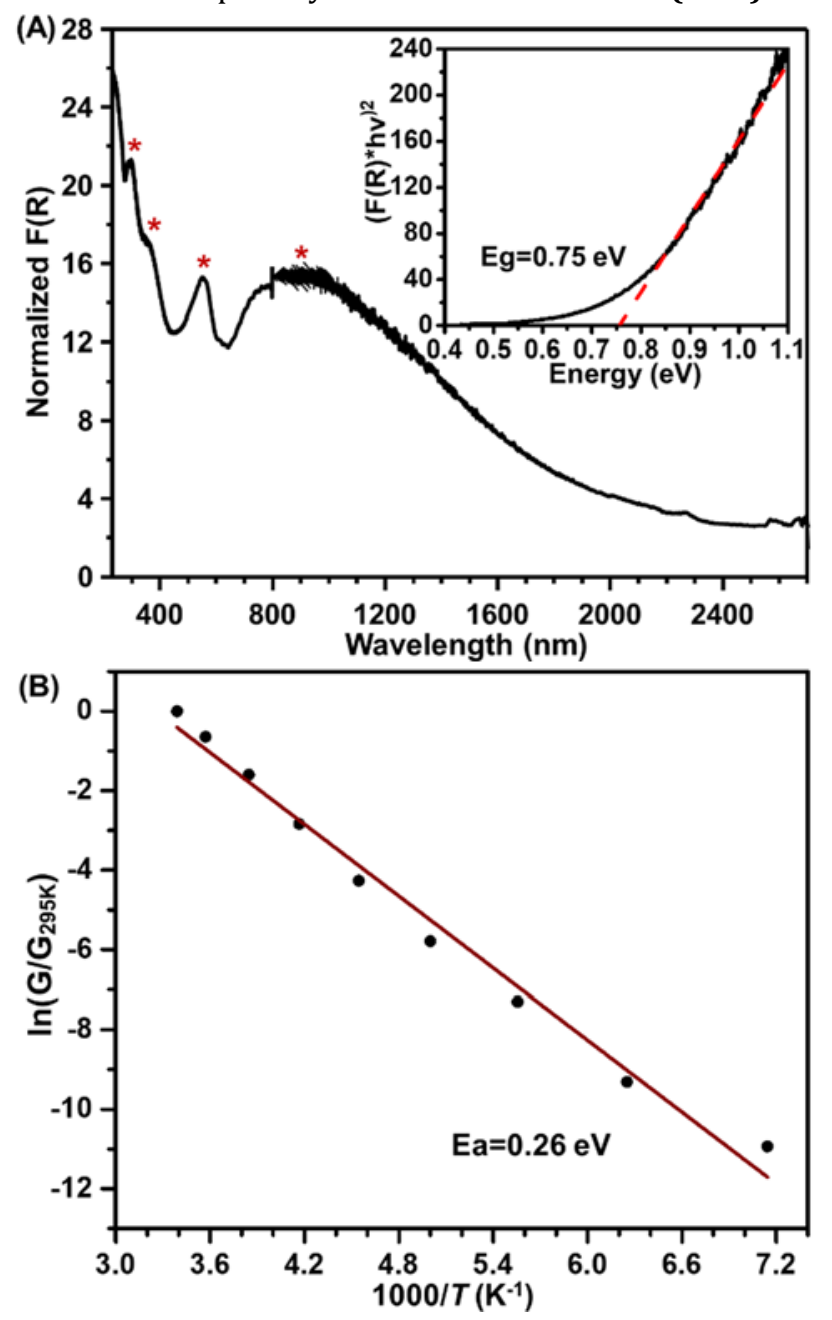

Figure 4. (A) UV-vis-NIR diffuse reflectance spectrum (four absorption features are marked; inflection around $800 \mathrm{~nm}$ is due to lamp change, $F(R)$ is the Kubelka-Munk conversion of the raw diffuse reflectance ). Inset is the Tauc plot with a direct band gap fitting (dashed line) for the near-IR feature. (B) Arrhenius fitting (red line) of the variable-temperature conductance $(\mathrm{G})$ data (black dots) by the equation of $G=G_{0} \exp \left(E_{a} / k T\right)$. 
Variable-temperature conductivity measurements over 140-295 K show that the conductance of the material increases with temperature, indicative of semiconducting behavior (Figure S18). Arrhenius fitting to the nearest-neighbours hopping ( $\mathrm{NNH}$ ) model ${ }^{14 e, 24}$ suggests a small activation energy $\left(\mathrm{E}_{\mathrm{a}}\right)$ of $0.26 \mathrm{eV}$ (Figure $4 \mathrm{~B}$ ). This value is similar to that reported for the $\mathbf{F e}_{\mathbf{8}}\left(\mathbf{C}_{6} \mathbf{O}_{6}\right)_{6}$ and $\mathbf{F e}_{12}\left(\mathbf{C}_{6} \mathbf{O}_{6}\right)_{6}$, which again can be ascribed to dual mixed-valency that facilitates redox-hopping between neighboring ligands or metal centers. ${ }^{16}$

The thermoelectric properties of $\mathbf{F e}_{\mathbf{5}}\left(\mathbf{C}_{\mathbf{6}} \mathbf{O}_{\mathbf{6}}\right)_{3}$ were also explored and the Seebeck coefficient was measured as +45.7 $\mu \mathrm{V} \mathrm{K}^{-1}$ at room temperature, suggesting a $\mathrm{p}$-type thermoelectric behavior (Figure S19). ${ }^{6}$ Combined with its comparatively high conductivity, $\mathbf{F e}_{5}\left(\mathbf{C}_{6} \mathbf{O}_{6}\right)_{3}$ is a promising candidate for thermoelectric conversion with further optimization. Interestingly, $\mathbf{F e}_{\mathbf{1 2}}\left(\mathbf{C}_{\mathbf{6}} \mathbf{O}_{\mathbf{6}}\right)_{\mathbf{6}}$ exhibits n-type thermoelectric behavior $\left(-130 \mu \mathrm{VK}^{-1}\right)$ with a lower conductivity $\left(2.7 \times 10^{-4} \mathrm{Scm}^{-1}\right)$ at room temperature. The calculated power factor $\left(S^{2} \sigma\right)$ is $4.2 \times 10^{-9} \mathrm{~W} \mathrm{~m}^{-1} \mathrm{~K}^{-2}$ for $\mathbf{F e}_{5}\left(\mathbf{C}_{6} \mathbf{O}_{6}\right)_{3}$ and $4.6 \times 10^{-10} \mathrm{~W} \mathrm{~m}^{-1} \mathrm{~K}^{-2}$ for $\mathbf{F e}_{12}\left(\mathbf{C}_{6} \mathbf{O}_{6}\right)_{6}$ respectively. These values are lower than those reported for 2D conductive MOFs. For instance, a high $S^{2} \sigma$ value of $8.3 \times 10^{-7} \mathrm{~W} \mathrm{~m}^{-1} \mathrm{~K}^{-2}$ has been reported for the hexaiminotriphenylene based MOF $\mathrm{Ni}_{3}(\mathrm{HITP})_{2}$ and a record of $2.0 \times 10^{-6} \mathrm{~W} \mathrm{~m}^{-1} \mathrm{~K}^{-2}$ was reported for the perthiolated coronene based MOF Ni-PTC. ${ }^{6 b, 6 d}$ The lower power factor of 3D materials is mostly ascribed to their lower electrical conductivity compared to the 2D conductive MOFs mentioned above, although both a high $\sigma$ and $S$ is desirable to achieve a high power factor. A critical disadvantage in these 3D materials is that redox hopping is the major contributor to conductivity while high metal-ligand covalency and strong in-plane $\pi$ - $d$ conjugation are more efficient for carrier transport in the 2D MOFs. ${ }^{1 \mathrm{~d}, 2 \mathrm{~d}, 18}$ As the primary challenge for developing high performance thermoelectric CPs/MOFs is improving charge carrier mobility, both "pre-synthetic" strategies (i.e. $\pi-d$ conjugation enhancement) and post-synthetic modifications (i.e., doping) are promising approaches for further optimization. ${ }^{6 a, 25}$

\section{Magnetic properties}

$\mathbf{F e}_{\mathbf{5}}\left(\mathbf{C}_{\mathbf{6}} \mathbf{O}_{6}\right)_{3}$ also displays interesting magnetic properties. DC magnetic susceptibility measurements were performed and the experimental $\chi_{\mathrm{M}} T$ per formula unit decreases almost linearly from $300 \mathrm{~K}$ to around $80 \mathrm{~K}$ (Figure 5A). This behavior suggests the existence of a dominant antiferromagnetic exchange coupling. Moreover, the observed $\chi_{\mathrm{M}} T$ value at $300 \mathrm{~K}$ is $9.53 \mathrm{~cm}^{3} \mathrm{~K} \mathrm{~mol}^{-1}$ for each $\mathbf{F e}_{5}\left(\mathbf{C}_{6} \mathbf{O}_{6}\right)_{3}$ unit. This value is much smaller than the estimated magnetically uncoupled spin-only value for the number of Fe and linker spin centers implied from Mössbauer analysis $\left(\chi_{\mathrm{M}} T \approx 20\right.$ $\mathrm{cm}^{3} \mathrm{~K} \mathrm{~mol}^{-1}$ ) which is also consistent with antiferromagnetic exchange. ${ }^{16 a}$ The presence of odd-electron linkers as well as mixed-valency between Fe centers suggests that superexchange, double exchange, and direct exchange pathways may all be present in $\mathbf{F e}_{\mathbf{5}}\left(\mathbf{C}_{6} \mathbf{O}_{6}\right)_{3}$. While assigning the agency and importance of specific coupling pathways is challenging due to this complexity, fitting the $\chi \mathrm{m}^{-1}$ data with the Curie-Weiss law from $300 \mathrm{~K}$ to $80 \mathrm{~K}$ shows a large Weiss constant $\left(\theta_{C W}\right)$ of $-400.7 \mathrm{~K}$, supporting dominant antiferromagnetic character (Figure 5A). Interestingly, $\mathbf{F e}_{\mathbf{1 2}}\left(\mathbf{C}_{\mathbf{6}} \mathbf{O}_{6}\right)_{6}$ also displays a decreasing $\chi_{\mathrm{M}} T$ with decreasing temperature. The Curie-Weiss fit of $\mathbf{F e}_{\mathbf{1 2}}\left(\mathbf{C}_{\mathbf{6}} \mathbf{O}_{6}\right)_{\mathbf{6}}$ gives a Weiss constant of $-219.37 \mathrm{~K}$ while the Co and $\mathrm{Mn}$ analogues have much smaller Weiss constants of $-73.86 \mathrm{~K}$ and $-47.95 \mathrm{~K}$ respectively.

In addition to the general antiferromagnetic trend in the susceptibility data, there is also a clear inflection at $\sim 30 \mathrm{~K}$ which displays some field dependence (Figure S20). Variable-temperature zero-field-cooled and field-cooled DC magnetization data (Figure S21) shows a divergence at $30 \mathrm{~K}$, likely suggesting some long-range interactions. ${ }^{26}$ We have attempted to interrogate this behavior with variable-temperature AC susceptibility measurements, however only weak signals were observed. The data shows a broad cusplike peak for the in-phase susceptiblity $\left(\chi_{\mathrm{m}}^{\prime}\right)$, and a noticeable rising anomaly for the out-of-phase susceptibility $\left(\chi_{\mathrm{m}}^{\prime \prime}\right)$ at around $10 \mathrm{~K}$ at low frequencies (Figure S22). While weak, these features may also be consistent with long-range magnetic interactions at low temperature.26,27 Variable field magnetization data were also collected at $10 \mathrm{~K}, 5 \mathrm{~K}$ and $2 \mathrm{~K}$, respectively. Each temperature indicates the presence of magnetic hysteresis, with corresponding coercive fields of $H_{C}=148$ Oe, 415 Oe, and 880 Oe respectively (Figure 5B, S23).

The complicated geometric pattern, multiple possible exchange interactions in the system, and the small AC signals
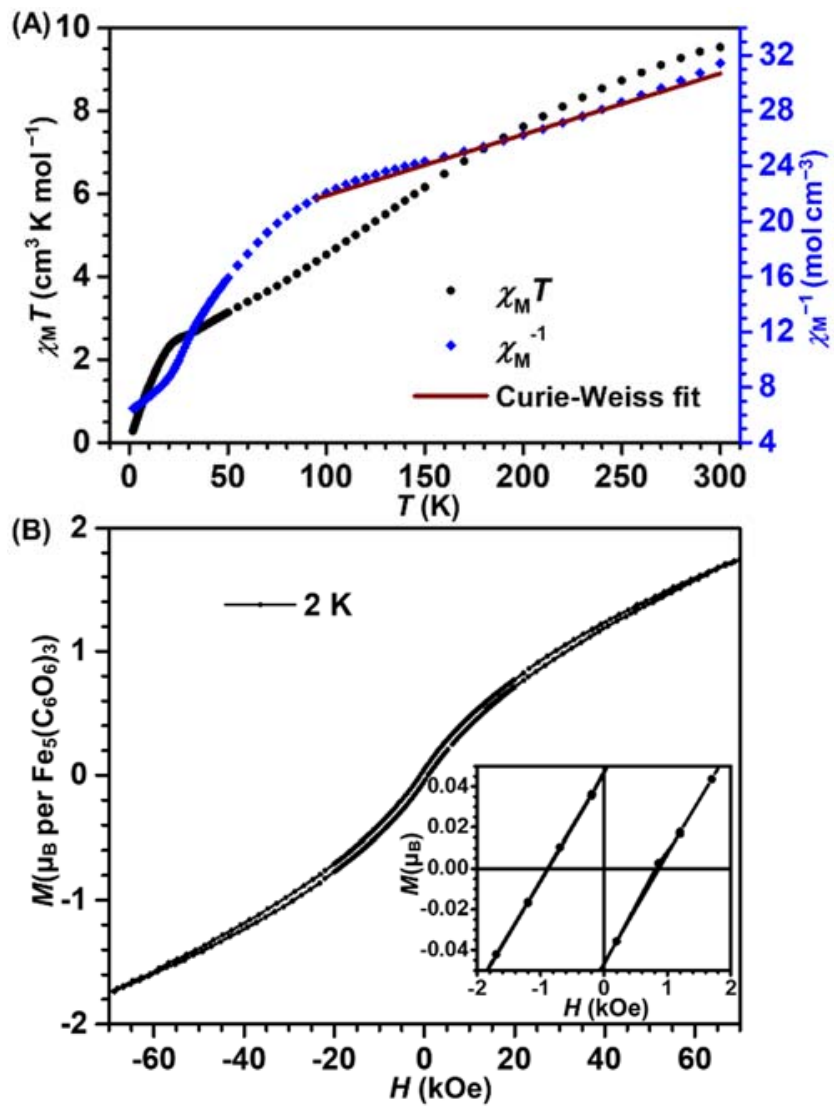

Figure 5. (A) Plot of $\chi_{\mathrm{M}} T, \chi^{-1}$ vs $T$ from $300 \mathrm{~K}$ to $2 \mathrm{~K}$ and the linear Curie-Weiss fit in the high temperature region from the equation of $\chi \mathrm{M}=C /\left(T-\theta_{C W}\right)$. $C$ is the Curie constant and $\theta_{C W}$ is the Weiss constant. (B) Variable-field magnetization data collected at $2 \mathrm{~K}$. Inset shows the coercive field of 880 Oe. 
make interpreting the magnetic behavior of this material challenging. A potential explanation for the data is a coexistence of antiferromagnetic and spin-glass states at low temperature, which could arise from strong coupling within the $2 \mathrm{D}$ planes with a relatively weak antiferromagnetic exchange between the layers giving rise to spin-canting due to the mirrored interlayer orientation. ${ }^{27,28}$ Indeed, strong intralayer and weak interlayer coupling in related hexagonal chloranilate frameworks have been observed and are dependent on the interlayer spacing. ${ }^{14 c, 23 b}$ Nevertheless, this proposal is speculative in our system and further studies, such as exchange of the interlayer metals with diamagnetic ions, will be required to thoroughly understand the magnetic behavior.

\section{Conclusions}

In summary, here we report a new 3D semiconducting material $\mathbf{F e}_{5}\left(\mathbf{C}_{6} \mathbf{O}_{6}\right)_{3}$ generated from Fe(II) and the most reduced version of HHB. This material is composed of $A B$ stacked hexagonal planes further bridged by Fe-O bonds to generate a 3D structure that features intrinsic dual mixed valency. The use of HHB as a linker precursor, instead of the more oxidized congener THQ, generates a material which is distinct from two previously reported $\mathbf{F e}_{12}\left(\mathbf{C}_{6} \mathbf{O}_{6}\right)_{6} / \mathbf{F e}_{\mathbf{8}}\left(\mathbf{C}_{6} \mathbf{O}_{6}\right)_{6}$ materials in terms of topology, connectivity, and the final oxidation states of the linkers. $\mathbf{F e}_{5}\left(\mathbf{C}_{6} \mathbf{O}_{6}\right)_{3}$ displays relatively high electrical conductivity, broad absorptions across the visible and near-IR region, interesting thermoelectric behavior, and strong antiferromagnetic interactions. Together these properties suggest that this material has promising applications in photosensing, efficient thermoelectric conversion, and magnetic studies. These results highlight that redox-active components with multiple accessible oxidation states can be an important synthetic parameter in exploring the phase-space of conductive CPs/MOFs via "bottom-up" synthetic strategies. This approach illustrates an avenue which is orthogonal to post-synthetic modifications to enrich the library of multifunctional conductive inorganic-organic hybrid materials.

\section{Experimental Section}

General consideration: All manipulations were performed under an inert atmosphere of dry $\mathrm{N}_{2}$ using a Schlenk line or MBraun UNIlab glovebox unless otherwise noted. Dimethylformamide (DMF), tetrahydrofuran (THF), diethyl ether $\left(\mathrm{Et}_{2} \mathrm{O}\right)$ and acetonitrile (MeCN) used in preparing the materials were initially dried and purged with $\mathrm{N}_{2}$ on a solvent purification system from Pure Process Technology. DMF and MeCN were then passed through activated alumina and stored over $4 \AA$ molecular sieves. THF and $\mathrm{Et}_{2} \mathrm{O}$ were stirred with liquid $\mathrm{NaK}$ alloy, filtered through activated alumina, and stored over $4 \AA$ molecular sieves. All other chemicals were purchased from commercial sources and used as received unless noted. NMR measurements were performed on Bruker DRX 400 spectrometers. Elemental analyses (C, H, N) were performed by Midwest Microlabs. $\mathbf{F e}_{\mathbf{8}}\left(\mathbf{C}_{\mathbf{6}} \mathbf{O}_{6}\right)_{\mathbf{6}}$ material was prepared according to the literature method. ${ }^{16 \mathrm{~b}}$

Synthesis of hexahydroxybenzene (HHB). The procedures were adapted from the literature. ${ }^{29}$ To a $250 \mathrm{~mL}$
Schlenk flask under $\mathrm{N}_{2}, 16 \mathrm{~mL}$ of a degassed $\mathrm{HCl}$ solution (2.4 M) was added via a plastic cannula. Sodium rhodizonate $(1.0 \mathrm{~g}, 4.7 \mathrm{mmol})$ was added and the solution was heated close to boiling. $\mathrm{SnCl}_{2} \cdot 2 \mathrm{H}_{2} \mathrm{O}$ (15.0 g, $\left.66.5 \mathrm{mmol}\right)$ was added to the solution, followed by the addition of $70 \mathrm{~mL}$ of a concentrated $\mathrm{HCl}$ solution. The mixture was allowed to cool to room temperature and was then placed in an ice bath to induce precipitation. White needles were then collected by filtration on a Schlenk frit under $\mathrm{N}_{2}$ and washed with $10 \mathrm{~mL}$ of degassed cold $\mathrm{EtOH} / \mathrm{HCl}$ (1:1). The crude product was redissolved in $36 \mathrm{~mL}$ of $2.4 \mathrm{M} \mathrm{HCl}$ (degassed by sparging with $\mathrm{N}_{2}$ ) and heated near to boiling. $100 \mathrm{mg}$ of decolorizing charcoal was then added and continued stirring for 10 mins under boiling. The solution was then filtered quickly through a Schlenk frit. The filtrate was cooled in an ice bath to form white needles under $\mathrm{N}_{2}$. Pure product was then collected and dried under vacuum to afford $813 \mathrm{mg}$ white solid (yield 64\%). ${ }^{13}$ C NMR (DMSO- $d_{6}$ ): 128 ppm.

Synthesis of material $\mathrm{Fe}_{5}\left(\mathrm{C}_{6} \mathrm{O}_{6}\right)_{3}(\mathrm{DMF})_{3}\left(\mathrm{H}_{2} \mathrm{O}\right)_{3}$. Anhydrous $\mathrm{FeCl}_{2}(1.2 \mathrm{mmol}, 150 \mathrm{mg}$ ) and hexahydroxybenzene $(0.60 \mathrm{mmol}, 105 \mathrm{mg}$ ) were combined in $15 \mathrm{~mL}$ of DMF in a vial. The reaction mixture was heated at $100^{\circ} \mathrm{C}$ for 3 days in the $\mathrm{N}_{2}$ filled glovebox. After cooling to room temperature, the mother liquor was decanted. The remaining solid was soaked in fresh DMF, further separated by centrifugation and washed sequentially $3 x$ each with DMF then $\mathrm{CH}_{3} \mathrm{CN}$. The resulting black powder was dried under vacuum overnight at room temperature (108 mg, 40\% yield). Different batches were combined for other characterizations. Solid used for $\mathrm{N}_{2}$ adsorption measurement was further solvent exchanged with DMF $\left(3 \times 20 \mathrm{~mL}, 50^{\circ} \mathrm{C}\right)$, THF $\left(3 \times 20 \mathrm{~mL}, 50^{\circ} \mathrm{C}\right)$ and $\mathrm{Et}_{2} \mathrm{O}$ $(3 \times 20 \mathrm{~mL})$ for 2 days of each. The solid was recycled after $\mathrm{N}_{2}$ adsorption and used for elemental analysis, thermogravimetric analysis, and FT-IR. FT-IR (KBr, $\left.\mathrm{cm}^{-1}\right)$ : $3420(\mathrm{~s}, \mathrm{br})$; 1648(s); 1501(m); 1403(s, br); 1111(w); 1050(s); 687(w). Anal. Calcd. for $\mathrm{Fe}_{5}\left(\mathrm{C}_{6} \mathrm{O}_{6}\right)_{3}\left(\mathrm{C}_{3} \mathrm{H}_{7} \mathrm{NO}\right)_{3}\left(\mathrm{H}_{2} \mathrm{O}\right)_{3}: \mathrm{C}, 30.69 ; \mathrm{H}$, 2.58 ; N, $3.98 \%$. Average found: C, 30.76; H, 2.40; N, $3.88 \%$.

X-Ray Powder Diffraction. Laboratory XRPD data were acquired on a Rigaku MiniFlex benchtop X-ray diffractometer equipped with $\mathrm{CuK} \alpha$ radiation in Bragg-Brentano reflection geometry (samples were exposed to air for 3 minutes during measurement; longer exposure to air will decrease the crystallinity dramatically, Figure S1). Synchrotron X-ray powder diffraction data collections were carried out at 295 $\mathrm{K}$ at beamline 11-BM of the Advanced Photon Source at Argonne National Laboratory using a calibrated wavelength of $\lambda=0.458095 \AA$ from 0.5 to $50^{\circ} 2 \theta .^{30 \mathrm{a}}$ The data were then further rebinned with a constant step size of $0.001^{\circ}$ to produce an equistepped pattern using PreDICT. ${ }^{30 \mathrm{~b}}$ The data outside of the $1.5^{\circ}-13.5^{\circ} 2 \theta$ range (corresponding to a $2 \AA$ spatial resolution) presented very little structural information and were excluded from the data analysis. The powder was sealed in boron-rich thin-walled capillary tubes to avoid air exposure.

Structure Determination: The search for a suitable unit cell using PREDICT/DICVOL14 ${ }^{30 b, 30 c}$ consistently reveals the same trigonal/hexagonal cell $a=24.6 \AA$, $c=14.9 \AA$, VOL = $7843 \AA 3$, with 5, 8 and 9 used indexing peaks, consistent with $Z=6$ (Figure S3, Table S2). The indexing results were then confirmed by an excellent LeBail fit ${ }^{31}$ in $P 6_{3}$ obtained from both diffractograms using the GSAS ${ }^{32}$ software (Figure 
S4). Only a single very weak Bragg peak at about $2 \theta=4.16^{\circ}$ remained unaccounted for (Figure S5). It should be noted that space group searches were generally inconclusive and several space groups such as $P 6_{3} \mathrm{~cm}, P 6_{1}, P 6_{1}, P 6_{2}, P 6_{3}, P 6_{4}$ and $P 6_{5}$ were subsequently tried with simulated annealing in order to select the most appropriate one, if any. The building block of $\left[\mathrm{Fe}_{2}\left(\mathrm{C}_{6} \mathrm{O}_{6}\right)_{3}\right]$ (a.k.a tripod) similar to a previous report ${ }^{14 c, 23 b}$ was modeled with a Python programming language, assuming $\mathrm{C}=\mathrm{O}=1.28 \AA$ and aromatic $\mathrm{C}-\mathrm{C}=1.38$ $\AA$. The length of a tripod leg should be $1 / 3$ of the lattice parameter $a$ thus resulting in a $\mathrm{Fe}-\mathrm{Fe}$ and $\mathrm{Fe}-\mathrm{O}$ distance of about $8.2 \AA$ and $2.24 \AA$, respectively. These tripods were then used for Simulated Annealing Global Optimization in FOX. ${ }^{33}$ The $P 6_{3}$ space group provided a chemically sensible molecular framework. Importantly, this space group suggests that the framework should have a ABAB staggered layered structure (Figure S8). It can be noted here that the high symmetry $P 6_{3} \mathrm{~cm}$ space group provided a potentially sensible layered framework, but the derived calculated XRPD pattern did not reproduce the two most intense 110 and 111 Bragg peaks and featured a huge 200 unobserved reflection at ca. $2.5^{\circ}$ (Figure S6). This model would also represent a not-staggered framework having large accessible solvent pores that is inconsistent with $\mathrm{N}_{2}$ uptake experiments. All other attempts failed to produce any sensible models (Figure S7). After choosing the $P 6_{3}$ space group and consequently the staggered framework model, the remaining $\mathrm{Fe}$ atoms (bridging two adjacent layers of tripods with 4-cooridnated Fe atoms) were added to the main framework according to the molecular formula of $\left[\mathrm{Fe}_{2}\left(\mathrm{C}_{6} \mathrm{O}_{6}\right)_{3}\right]\left[\mathrm{Fe}\left(\mathrm{H}_{2} \mathrm{O}\right)\left(\mathrm{C}_{3} \mathrm{H}_{7} \mathrm{NO}\right)\right]_{3}$. The 4-coordinated Fe (41, $44,47)$ are placed into a framework in such a way that they have similar interatomic distances (7.362 $\AA$ ) within the same horizontal plane (perpendicular to the $c$-axis, Figure S8). Once the 4-coordinated Fe atoms were placed, the remaining two 0 -atoms were attached assuming regular tetrahedra. Presumably, one oxygen atom is coming from a water solvent molecule, whereas the other belongs to a DMF molecule based on combustion analysis (Figure S9). The orientation of the $\mathrm{FeO}_{4}$ tetrahedra was chosen in such a way that all $\mathrm{Fe}_{\text {tetrahedral }}-\mathrm{Fe}_{\text {tetrahedral }}$ neighboring distances were identical, resulting in a Fe-Fe distance of 7.362 Å. It can be noted that this partial crystallographic model reveals that the two extraneous $\mathrm{O}$-atoms attached to the tetrahedral $\mathrm{Fe}$ atoms represent two distinct groups of 0-atoms: 043, 045, 048 (located at $3.8 \AA$ from each other) and 042, 046, 049 (located at $4.9 \AA$ from each other). While it was not possible to elucidate the precise solvent spatial positions in the framework voids, such a distribution may suggest that the first group pertains to the water molecules and the second to the DMF molecules. Despite the missing DMF molecules, a Rietveld refinement revealed an acceptable fit for the experimental data. The GSAS-borne least-squares refinement utilized a mild preferred orientation modeled by spherical harmonics up to the order of 6 associated with a moderate texture index of 1.7 (Table S3, Figure S10).

Thermogravimetric Analysis (TGA). TGA was performed using a TA Instruments Discovery analyzer. Approximately $2 \mathrm{mg}$ of sample was loaded into a pre-tared Pt pan and measured from ambient to $600{ }^{\circ} \mathrm{C}$ using a linear temperature ramp of $3{ }^{\circ} \mathrm{C} / \mathrm{min}$ under $\mathrm{N}_{2}$.
Nitrogen Adsorption Measurements. Crystalline solid was transferred to a pre-weighed analysis tube in the glovebox and capped with a Transeal. The sample tube was then transferred to a Micrometrics ASAP 2020 Plus gas adsorption analyzer and degassed at a rate of $1.0{ }^{\circ} \mathrm{C} / \mathrm{min}$ from room temperature to a final temperature of $70^{\circ} \mathrm{C}$. The sample was further activated at $70^{\circ} \mathrm{C}$ for one week until an outgas rate of less than $1 \mathrm{mTorr} / \mathrm{min}$ was observed. The $\mathrm{N}_{2}$ adsorption isotherm at $77 \mathrm{~K}$ was measured in liquid nitrogen. After the experiment, the PXRD pattern of the sample was checked, and the crystallinity was maintained (Figure S1). A separate previous trial showed the sample was totally amorphous if degassed at $120^{\circ} \mathrm{C}$.

Scanning Electron Microscopy. Scanning electron microscope (SEM) images were taken on the Carl Zeiss Merlin using the In-Lens detector in the Materials Research Science and Engineering Center (MRSEC) at the University of Chicago. The accelerating voltage is $5.00 \mathrm{kV}$.

X-ray Photoelectron Spectroscopy. X-ray photoelectron spectra (XPS) were collected with the AXIS Nova spectrometer (Kratos Analytical) equipped with a monochro-

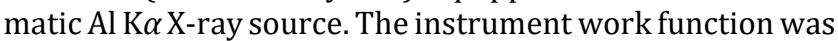
calibrated to give an $\mathrm{Au} 4 \mathrm{f}_{7 / 2}$ metallic gold binding energy of $83.95 \mathrm{eV}$. For calibration purposes, the binding energies were referenced to C $1 \mathrm{~s}$ peak at $284.8 \mathrm{eV}$. Survey spectra were collected with a step size of 1 and $160 \mathrm{eV}$ pass energy. The high-resolution spectra were collected with a pass energy of 40 and $0.1 \mathrm{eV}$ step size. Pressed pellets of samples were affixed to conductive carbon tape in $\mathrm{N}_{2}$ filled glovebox before loading into the spectrometer.

Mössbauer Spectroscopy. Zero-field iron-57 Mössbauer spectrum were obtained at $77 \mathrm{~K}$ with a constant acceleration spectrometer and a cobalt-57 rhodium source. Prior to measurements, the spectrometer was calibrated at $295 \mathrm{~K}$ with $\alpha$-iron foil. The sample was encased in Paratone- $\mathrm{N}$ oil and placed in a polyethylene sample cup inside a $\mathrm{N}_{2}$ filled glovebox. The spectra were analyzed using the WMOSS Mössbauer Spectral Analysis Software (www.wmoss.org).

FT-IR Spectroscopy. Powder samples for FT-IR were pressed into pellets in a potassium bromide matrix. Spectra were acquired in transmission mode on a Bruker Tensor II spectrometer with MCT detector operated at 77 K. Data was processed with background subtractions.

UV-Vis-NIR Spectroscopy. Solution UV-Vis spectra were collected on Thermo Scientific Evolution 300 spectrometer. Solid UV-vis-NIR diffuse reflectance spectra were collected on a Thermo Scientific Evolution 300 spectrometer and a CARY 5000 spectrophotometer with powder samples loaded in a Praying Mantis air-free diffuse reflectance cell with $\mathrm{KBr}$ powder as the non-adsorbing matrix. The $\mathrm{Ku}$ belka-Munk conversion of the raw diffuse reflectance spectrum was obtained by applying the formula $F(R)=$ $(1-R)^{2} / 2 R$.

Conductivity Measurements. Room temperature electrical conductivity measurements were performed in a twocontact geometry using a BASi Epsilon potentiostation/Galvano station fitted to an $\mathrm{N}_{2}$ glovebox. Samples were prepared as pressed pellets clamped between two brass electrodes ( $4.8 \mathrm{~mm}$ diam, $0.178 \mathrm{~cm}^{2}$ area.) in a glass sleeve using a hand press. Sample pellet thicknesses were measured 
with a caliper and were typically in the range of 200 to 500 $\mu \mathrm{m}$. Linear sweep voltammetry was conducted with the reference and counter electrode terminals connected to one electrode and the working electrode terminal to the other. The resulting data were fit to a straight line to obtain the sample resistance. Variable-temperature electrical conductivity measurements were performed under vacuum through a custom design using NIPCI-6221 DAQ, Standford Research Systems SR570 current preamplifier and Montana Instruments S50 cryostation. Sample pellets were prepared in the glovebox using a hand press and fitted to a customized cell ( $4 \mathrm{~mm}^{*} 2 \mathrm{~mm}^{*} 1 \mathrm{~mm}$ ) made of ceramic (Figure S18a). The cell has copper wire contacting points at each corner and can be sealed with a fitted lid through screws. Ohmic $I-V$ profiles were observed for all temperatures from $140 \mathrm{~K}$ to $295 \mathrm{~K}$ with a $20 \mathrm{~K}$ interval, and a linear fit of the $\mathrm{I}-\mathrm{V}$ curve was used to get the conductance $(G)$ of the sample.

Seebeck Coefficient Measurement. The Seebeck coefficient measurement were performed using a custom-designed probe station in an argon glovebox. ${ }^{34}$ Around $20 \mathrm{mg}$ sample powder was pressed into a pellet with a diameter of $8 \mathrm{~mm}$ using a TMAX Laboratory Manual Hydraulic Press under a pressure of 3 ton. Gold electrical contacts $(\sim 75 \mathrm{~nm}$ thick) were deposited onto the pressed pellet $(\sim 160 \mu \mathrm{m}$ thick) of bulk sample powder via thermal evaporation (Figure S19a). Two thermocouples were used to collect the hot and cold side temperatures, and another two probes were used to measure the corresponding voltage value. A delay of $200 \mathrm{~s}$ was adopted for voltage measurements to allow a steady-state temperature gradient and voltage. The Seebeck coefficient was calculated from the slope of a linear fit for the $\Delta \mathrm{V}$ vs $\Delta T$ plot.

Magnetic Measurements. Magnetic measurements were performed on a Quantum Design MPMS3 SQUID magnetometer. The bulk powder of the sample (29.0 mg) was suspended in an eicosane matrix in a polycarbonate capsule to prevent movement and protect the sample from incidental air exposure. Diamagnetic corrections for the capsule and eicosane were made by measuring temperature vs moment in triplicate for each to determine a moment per gram correction. Diamagnetic corrections for the sample itself was applied using Pascal's constants of each atom based on the formula of $\mathrm{Fe}_{5}\left(\mathrm{C}_{6} \mathrm{O}_{6}\right)_{3}\left(\mathrm{H}_{2} \mathrm{O}\right)_{3}\left(\mathrm{C}_{3} \mathrm{H}_{7} \mathrm{NO}\right)_{3}$.

\section{ASSOCIATED CONTENT}

\section{Supporting Information}

Additional experimental details and characterization data are included in supporting information. The Supporting Information is available free of charge on the ACS Publications website.

\section{AUTHOR INFORMATION}

\section{Corresponding Author}

jsanderson@uchicago.edu

\section{ORCID}

Lei Wang: 0000-0002-3778-2814

Robert J. Papoular: 0000-0002-4557-5794
Jiaze Xie: 0000-0003-1813-9521

Norman Zhao: 0000-0001-7097-0617

Tengzhou Ma: 0000-0002-9116-5518

Alexander S. Filatov: 0000-0002-8378-1994

John S. Anderson: 0000-0002-0730-3018

Notes

The authors declare no competing financial interests.

\section{ACKNOWLEDGMENT}

This research was supported by the U.S. National Science Foundation (DMR- 2002367). Use of the Advanced Photon Source at 11-BM at Argonne National Laboratory was supported by the U.S. Department of Energy, Office of Science, Office of Basic Energy Sciences, under Contract DE-AC02-06CH11357. We thank Dr. Shrayesh N. Patel for Seebeck coefficient measurements. We also thank Professor Danna Freedman as well as Daniel Laorenza and Kelsey A. Collins (Northwestern University) for assistance with UV-Vis-NIR and Mössbauer spectroscopy.

\section{REFERENCES}

1. (a) D'Alessandro, D. M.; Kanga, J. R. R.; Caddy, J. S. Towards Conducting Metal-Organic Frameworks. Aust. J. Chem. 2011, 64, 718-722. (b) Hendon, C. H.; Tiana, D.; Walsh, A. Conductive MetalOrganic Frameworks And Networks: Fact Or Fantasy? Phys. Chem. Chem. Phys. 2012, 14, 13120-13132. (c) Sun, L.; Campbell, M. G.; Dincă, M. Electrically Conductive Porous Metal-Organic Frameworks. Angew. Chem., Int. Ed. 2016, 55, 3566-3579. (d) Xie, L. S.; Skorupskii, G.; Dincă, M. Electrically Conductive Metal-Organic Frameworks. Chem. Rev. 2020, 120, 8536-8580. (e) Rubio-Giménez, V.; Tatay, S.; Martí-Gastaldo, C. Electrical Conductivity and Magnetic Bistability in Metal-Organic Frameworks and Coordination Polymers: Charge Transport and Spin Crossover At The Nanoscale. Chem. Soc. Rev. 2020, 49, 5601-5638. (f) Kung, C.-W.; Goswami, S.; Hod, I.; Wang, T. C.; Duan, J.; Farha, O. K.; Hupp, J. T. Charge Transport in Zirconium-Based Metal-Organic Frameworks. Acc. Chem. Res. 2020, 53, 1187-1195.

2. (a) Ko, M.; Mendecki, L.; Mirica, K. A. Conductive Two-Dimensional Metal-Organic Frameworks as Multifunctional Materials. Chem. Commun. 2018, 54, 7873-7891. (b) Allendorf, M. D.; Dong, R.; Feng, X.; Kaskel, S.; Matoga, D.; Stavila, V. Electronic Devices Using Open Framework Materials. Chem. Rev. 2020, 120, 8581-8640. (c) Wang, M.; Dong, R.; Feng, X. Two-Dimensional Conjugated Metal-Organic Frameworks (2D c-MOFs): Chemistry and Function For MOFtronics. Chem. Soc. Rev. 2021, 50, 2764-2793. (d) Li, C.; Zhang, L.; Chen, J.; Li, X.; Sun, J.; Zhu, J.; Wang, X.; Fu, Y. Recent Development and Applications of Electrical Conductive MOFs. $\mathrm{Na}$ noscale 2021, 13, 485-509.

3. (a) Stassen, I.; Burtch, N.; Talin, A.; Falcaro, P.; Allendorf, M.; Ameloot, R. An Updated Roadmap for the Integration of Metal-Organic Frameworks with Electronic Devices and Chemical Sensors. Chem. Soc. Rev., 2017, 46, 3185-3241. (b) Campbell, M. G.; Sheberla, D.; Liu, S. F.; Swager, T. M.; Dincă, M. Cuз (hexaiminotriphenylene)2: An Electrically Conductive 2D Metal-Organic Framework for Chemiresistive Sensing. Angew. Chem. Int. Ed., 2015, 54, 4349-4352. (c) Huang, J.; He, Y.; Yao, M.-S.; He, J.; Xu, G.; Zeller, M.; $\mathrm{Xu}, \mathrm{Z}$. A Semiconducting Gyroidal Metal-Sulfur Framework for Chemiresistive Sensing. J. Mater. Chem. A. 2017, 5, 16139-16143.

4. (a) Liu, J.; Song, X.; Zhang, T.; Liu, S.; Wen, H.; Chen, L. 2D Conductive Metal-Organic Frameworks: An Emerging Platform for Electrochemical Energy Storage. Angew. Chem. Int. Ed., 2021, 60, 5612-5624. (b) Sheberla, D.; Bachman, J. C.; Elias, J. S.; Sun, C.-J.; Shao-Horn, Y.; Dincă, M. Conductive MOF Electrodes for Stable Supercapacitors with High Areal Capacitance. Nat. Mater. 2017, 16, 220-224. (c) Feng, D.; Lei, T.; Lukatskaya, M. R.; Park, J.; Huang, Z.; Lee, M.; Shaw, L.; Chen, S.; Yakovenko, A. A.; Kulkarni, A.; Xiao, J.; Fredrickson, K.; Tok, J. B.; Zou, X.; Cui, Y.; Bao, Z. Robust and 
Conductive Two-Dimensional Metal-Organic Frameworks with Exceptionally High Volumetric and Areal Capacitance. Nat. Energy 2018, 3, 30-36. (d) Nam, K. W.; Park, S. S.; dos Reis, R.; Dravid, V. P.; Kim, H.; Mirkin, C. A.; Stoddart, J. F. Conductive 2D Metal-Organic Framework for High-Performance Cathodes in Aqueous Rechargeable Zinc Batteries. Nat. Commun. 2019, 10, 4948. (e) Jiang, Q.; Xiong, P.; Liu, J.; Xie, Z.; Wang, Q.; Yang, X.-Q.; Hu, E.; Cao, Y.; Sun, J.; $\mathrm{Xu}$, Y.; Chen, L. A Redox-Active 2D Metal-Organic Framework for Efficient Lithium Storage with Extraordinary High Capacity. Angew. Chem. Int. Ed., 2020, 59, 5273-5277. (f) Ziebel, M. E.; Gaggioli, C. A.; Turkiewicz, A. B.; Ryu, W.; Gagliardi, L.; Long, J. R. Effects of Covalency on Anionic Redox Chemistry in Semiquinoid-Based Metal-Organic Frameworks. J. Am. Chem. Soc. 2020, 142, 26532664.

5. (a) Stavila, V.; Talin, A. A.; Allendorf, M. D. MOF-based Electronic and Opto-Electronic Devices. Chem. Soc. Rev. 2014, 43, 5994-6010. (b) Liu, H.; Wang, Y.; Qin, Z.; Liu, D.; Xu, H.; Dong, H.; $\mathrm{Hu}, \mathrm{W}$. Electrically Conductive Coordination Polymers for Electronic and Optoelectronic Device Applications. J. Phys. Chem. Lett. 2021, 12, 1612-1630. (c) Arora, H.; Dong, R.; Venanzi, T.; Zscharschuch, J.; Schneider, H.; Helm, M.; Feng, X.; Cánovas, E.; Erbe, A. Demonstration of a Broadband Photodetector Based on a Two-Dimensional Metal-Organic Framework. Adv. Mater. 2020, 32, 1907063.

6. (a) Lu, Y.; Young, D. J. Coordination Polymers for n-type Thermoelectric Applications. Dalton Trans. 2020, 49, 7644-7657. (b) Sun, L.; Liao, B.; Sheberla, D.; Kraemer, D.; Zhou, J.; Stach, E. A.; Zakharov, D.; Stavila, V.; Talin, A. A.; Ge, Y.; Allendorf, M. D.; Chen, G.; Léonard, F.; Dincă, M. A Microporous and Naturally Nanostructured Thermoelectric Metal-Organic Framework with Ultralow Thermal Conductivity. Joule 2017, 1, 168-177. (c) Park, J.; Hinckley, A. C.; Huang, Z.; Chen, G.; Yakovenko, A. A.; Zou, X.; Bao, Z. High Thermopower in a Zn-Based 3D Semiconductive Metal-Organic Framework. J. Am. Chem. Soc. 2020, 142, 20531-20535. (d) Chen, Z.; Cui, Y.; Jin, Y.; Liu, L.; Yan, J.; Sun, Y.; Zou, Y.; Sun, Y.; Xu, W.; Zhu, D. Nanorods of a Novel Highly Conductive 2D Metal-Organic Framework Based on Perthiolated Coronene for Thermoelectric Conversion. J. Mater. Chem. C. 2020, 8, 8199-8205.

7. (a) Thorarinsdottir, A. E.; Harris, T. D. Metal-Organic Framework Magnets. Chem. Rev. 2020, 120, 8716-8789. (b) Song, X.; Wang, X.; Li, Y.; Zheng, C.; Zhang, B.; Di, C.-a.; Li, F.; Jin, C.; Mi, W.; Chen, L.; Hu, W. 2D Semiconducting Metal-Organic Framework Thin Films for Organic Spin Valves. Angew. Chem. Int. Ed., 2020, 59, 1118-1123. (c) Misumi, Y.; Yamaguchi, A.; Zhang, Z.; Matsushita, T.; Wada, N.; Tsuchiizu, M.; Awaga, K. Quantum Spin Liquid State in a Two-Dimensional Semiconductive Metal-Organic Framework. J. Am. Chem. Soc. 2020, 142, 16513-16517.

8. (a) Dong, R.; Han, P.; Arora, H.; Ballabio, M.; Karakus, M.; Zhang, Z.; Shekhar, C.; Adler, P.; Petkov, P. S.; Erbe, A.; Mannsfeld, S. C. B.; Felser, C.; Heine, T.; Bonn, M.; Feng, X.; Cánovas, E. High-mobility band-like charge transport in a semiconducting two-dimensional metal-organic framework. Nat. Mater. 2018, 17, 10271032. (b) Day, R. W.; Bediako, D. K.; Rezaee, M.; Parent, L. R.; Skorupskii, G.; Arguilla, M. Q.; Hendon, C. H.; Stassen, I.; Gianneschi, N. C.; Kim, P.; Dincă, M. Single Crystals of Electrically Conductive Two-Dimensional Metal-Organic Frameworks: Structural and Electrical Transport Properties. ACS Cent. Sci. 2019, 5, 1959-1964. (c) Nyakuchena, J.; Ostresh, S.; Streater, D.; Pattengale, B.; Neu, J.; Fiankor, C.; Hu, W.; Kinigstein, E. D.; Zhang, J.; Zhang, X.; Schmuttenmaer, C. A.; Huang, J. Direct Evidence of Photoinduced Charge Transport Mechanism in 2D Conductive Metal Organic Frameworks. J. Am. Chem. Soc. 2020, 142, 21050-21058. (d) Dou, J.-H.; Arguilla, M. Q.; Luo, Y.; Li, J.; Zhang, W.; Sun, L.; Mancuso, J. L.; Yang, L.; Chen, T.; Parent, L. R.; Skorupskii, G.; Libretto, N. J.; Sun, C.; Yang, M. C.; Dip, P. V.; Brignole, E. J.; Miller, J. T.; Kong, J.; Hendon, C. H.; Sun, J.; Dincă, M. Atomically Precise Single-Crystal Structures of Electrically Conducting 2D Metal-Organic Frameworks. Nat. Mater. 2021, 20, 222-228.
9. (a) Chen, S.; Dai, J.; Zeng, X. C. Metal-Organic Kagome Lattices $\mathrm{M}_{3}(2,3,6,7,10,11 \text {-hexaiminotriphenylene })_{2}(\mathrm{M}=\mathrm{Ni}$ and $\mathrm{Cu})$ : from Semiconducting to Metallic by Metal Substitution. Phys. Chem. Chem. Phys 2015, 17, 5954-5958. (b) Foster, M. E.; Sohlberg, K.; Spataru, C. D.; Allendorf, M. D. Proposed Modification of the Graphene Analogue $\mathrm{Ni}_{3}(\mathrm{HITP})_{2}$ To Yield a Semiconducting Material. J. Phys. Chem. C 2016, 120, 15001-15008. (c) Zojer, E.; Winkler, C. Maximizing the Carrier Mobilities of Metal-Organic Frameworks Comprising Stacked Pentacene Units. J. Phys. Chem. Lett 2021, 12, 7002-7009. (d) Le, K. N.; Mancuso, J. L.; Hendon, C. H. Electronic Challenges of Retrofitting 2D Electrically Conductive MOFs to Form 3D Conductive Lattices. ACS Appl. Electron. Mater. 2021, 3, 20172023. (e) Zhang, Z.; Dell'Angelo, D.; Momeni, M. R.; Shi, Y.; Shakib, F. A. Metal-to-Semiconductor Transition in Two-Dimensional Metal-Organic Frameworks: An Ab Initio Dynamics Perspective. ACS Appl Mater Interfaces 2021, 13, 25270-25279.

10. (a) Maeda, H.; Sakamoto, R.; Nishihara, H. Coordination Programming of Two-Dimensional Metal Complex Frameworks. Langmuir 2016, 32, 2527-2538. (b) Hmadeh, M.; Lu, Z.; Liu, Z.; Gándara, F.; Furukawa, H.; Wan, S.; Augustyn, V.; Chang, R.; Liao, L.; Zhou, F.; Perre, E.; Ozolins, V.; Suenaga, K.; Duan, X.; Dunn, B.; Yamamto, Y.; Terasaki, O.; Yaghi, O. M. New Porous Crystals of Extended MetalCatecholates. Chem. Mater 2012, 24, 3511-3513. (c) Kambe, T.; Sakamoto, R.; Kusamoto, T.; Pal, T.; Fukui, N.; Hoshiko, K.; Shimojima, T.; Wang, Z.; Hirahara, T.; Ishizaka, K.; Hasegawa, S.; Liu, F.; Nishihara, H. Redox Control and High Conductivity of Nickel Bis(dithiolene) Complex $\pi$-Nanosheet: A Potential Organic Two-Dimensional Topological Insulator. J. Am. Chem. Soc. 2014, 136, 14357-14360. (d) Dou, J.-H.; Sun, L.; Ge, Y.; Li, W.; Hendon, C. H.; Li, J.; Gul, S.; Yano, J.; Stach, E. A.; Dincă, M. Signature of Metallic Behavior in the MetalOrganic Frameworks $\mathrm{M}_{3}$ (hexaiminobenzene) $2(\mathrm{M}=\mathrm{Ni}, \mathrm{Cu}$ ). J. Am. Chem. Soc. 2017, 139, 13608-13611. (e) Park, J.; Hinckley, A. C.; Huang, Z.; Feng, D.; Yakovenko, A. A.; Lee, M.; Chen, S.; Zou, X.; Bao, Z. Synthetic Routes for a 2D Semiconductive Copper Hexahydroxybenzene Metal-Organic Framework. J. Am. Chem. Soc. 2018, 140, 14533-14537. (f) Huang, X.; Qiu, Y.; Wang, Y.; Liu, L.; Wu, X.; Liang, Y.; Cui, Y.; Sun, Y.; Zou, Y.; Zhu, J.; Fang, W.; Sun, J.; Xu, W.; Zhu, D. Highly Conducting Organic-Inorganic Hybrid Copper Sulfides $\mathrm{Cu}_{\mathrm{x}} \mathrm{C}_{6} \mathrm{~S}_{6}(\mathrm{x}=4$ or 5.5): Ligand-Based Oxidation-Induced Chemical and Electronic Structure Modulation. Angew. Chem. Int. Ed., 2020, 59, 22602-22609. (g) Yadav, A.; Panda, D. K.; Zhang, S.; Zhou, W.; Saha, S. Electrically Conductive 3D Metal-Organic Framework Featuring $\pi$-Acidic Hexaazatriphenylene Hexacarbonitrile Ligands with Anion- $\pi$ Interaction and Efficient Charge-Transport Capabilities. ACS Appl Mater Interfaces 2020, 12, 40613-40619.

11. (a) Eddaoudi, M.; Moler, D. B.; Li, H.; Chen, B.; Reineke, T. M.; O'Keeffe, M.; Yaghi, O. M. Modular Chemistry: Secondary Building Units as a Basis for the Design of Highly Porous and Robust Metal-Organic Carboxylate Frameworks. Acc. Chem. Res. 2001, 34, 319-330. (b) Zhao, D.; Timmons, D. J.; Yuan, D.; Zhou, H.-C. Tuning the Topology and Functionality of Metal-Organic Frameworks by Ligand Design. Acc. Chem. Res. 2011, 44, 123-133. (c) Yaghi, O. M.; O'Keeffe, M.; Ockwig, N. W.; Chae, H. K.; Eddaoudi, M.; Kim, J. Reticular Synthesis and the Design of new Materials. Nature 2003, 423, 705-714. (d) Jiang, H.-L.; Makal, T. A.; Zhou, H.-C. Interpenetration Control in Metal-Organic Frameworks for Functional Applications. Coord. Chem. Rev. 2013, 257, 2232-2249.

12. (a) Zhang, Y.; Riduan, S. N.; Wang, J. Redox Active Metal- and Covalent Organic Frameworks for Energy Storage: Balancing Porosity and Electrical Conductivity. Chem. Eur. J. 2017, 23, 1641916431. (b) Murase, R.; Leong, C. F.; D’Alessandro, D. M. Mixed Valency as a Strategy for Achieving Charge Delocalization in Semiconducting and Conducting Framework Materials. Inorg. Chem. 2017, 56, 14373-14382. (c) Chen, J.; Sekine, Y.; Komatsumaru, Y.; Hayami, S.; Miyasaka, H. Thermally Induced Valence Tautomeric Transition in a Two-Dimensional Fe-Tetraoxolene Honeycomb Network. Angew. Chem. Int. Ed., 2018, 57, 12043-12047. (d) Calbo, J.; Golomb, M. J.; Walsh, A. Redox-Active Metal-Organic Frameworks for Energy Conversion And Storage. J. Mater. Chem. A. 2019, 
7, 16571-16597. (e) Souto, M.; Strutyński, K.; Melle-Franco, M.; Rocha, J. Electroactive Organic Building Blocks for the Chemical Design of Functional Porous Frameworks (MOFs and COFs) in Electronics. Chem. Eur. J. 2020, 26, 10912-10935. (f) Ding, B.; Solomon, M. B.; Leong, C. F.; D'Alessandro, D. M. Redox-active Ligands: Recent Advances Towards Their Incorporation into Coordination Polymers and Metal-Organic Frameworks. Coord. Chem. Rev. 2021, 439, 213891.

13. Sun, L.; Hendon, C. H.; Park, S. S.; Tulchinsky, Y.; Wan, R.; Wang, F.; Walsh, A.; Dincă, M. Is Iron Unique In Promoting Electrical Conductivity in MOFs? Chem. Sci. 2017, 8, 4450-4457.

14. (a) Mercuri, M. L.; Congiu, F.; Concas, G.; Sahadevan, S. A. Recent Advances on Anilato-Based Molecular Materials with Magnetic and/or Conducting Properties. Magnetochemistry 2017, 3, 17. (b) Darago, L. E.; Aubrey, M. L.; Yu, C. J.; Gonzalez, M. I.; Long, J. R. Electronic Conductivity, Ferrimagnetic Ordering, and Reductive Insertion Mediated by Organic Mixed-Valence in a Ferric Semiquinoid Metal-Organic Framework. J. Am. Chem. Soc. 2015, 137, 15703-15711. (c) DeGayner, J. A.; Jeon, I.-R.; Sun, L.; Dincă, M.; Harris, T. D. 2D Conductive Iron-Quinoid Magnets Ordering up to $T \mathrm{c}=$ 105 K via Heterogenous Redox Chemistry. J. Am. Chem. Soc. 2017, 139, 4175-4184. (d) DeGayner, J. A.; Wang, K.; Harris, T. D. A Ferric Semiquinoid Single-Chain Magnet via Thermally-Switchable Metal-Ligand Electron Transfer. J. Am. Chem. Soc. 2018, 140, 65506553. (e) Ziebel, M. E.; Darago, L. E.; Long, J. R. Control of Electronic Structure and Conductivity in Two-Dimensional Metal-Semiquinoid Frameworks of Titanium, Vanadium, and Chromium. $J$. Am. Chem. Soc. 2018, 140, 3040-3051. (f) Sahadevan, S. A.; Abhervé, A.; Monni, N.; Sáenz de Pipaón, C.; Galán-Mascarós, J. R.; Waerenborgh, J. C.; Vieira, B. J. C.; Auban-Senzier, P.; Pillet, S.; Bendeif, E.-E.; Alemany, P.; Canadell, E.; Mercuri, M. L.; Avarvari, N. Conducting Anilate-Based Mixed-Valence Fe(II)Fe(III) Coordination Polymer: Small-Polaron Hopping Model for Oxalate-Type Fe(II)Fe(III) 2D Networks. J. Am. Chem. Soc.2018, 140, 1261112621. (g) Murase, R.; Commons, C. J.; Hudson, T. A.; Jameson, G. N. L.; Ling, C. D.; Murray, K. S.; Phonsri, W.; Robson, R.; Xia, Q.; Abrahams, B. F.; D'Alessandro, D. M. Effects of Mixed Valency in an FeBased Framework: Coexistence of Slow Magnetic Relaxation, Semiconductivity, and Redox Activity. Inorg. Chem. 2020, 59, 36193630.

15. Chen, H.; Armand, M.; Courty, M.; Jiang, M.; Grey, C. P.; Dolhem, F.; Tarascon, J.-M.; Poizot, P. Lithium Salt of Tetrahydroxybenzoquinone: Toward the Development of a Sustainable LiIon Battery. J. Am. Chem. Soc. 2009, 131, 8984-8988.

16. (a) Wu, X.; Qiu, Y.; Chen, Z.; Guan, B.; Hao, X.; Rykov, A. I.; Sun, Y.; Liu, L.; Zou, Y.; Sun, J.; Xu, W.; Zhu, D. Paramagnetic Conducting Metal-Organic Frameworks with Three-Dimensional Structure. Angew. Chem. Int. Ed., 2020, 59, 20873-20878. (b) Chen, G.; Gee, L. B.; Xu, W.; Zhu, Y.; Lezama-Pacheco, J. S.; Huang, Z.; Li, Z.; Babicz, J. T.; Choudhury, S.; Chang, T.-H.; Reed, E.; Solomon, E. I.; Bao, Z. Valence-Dependent Electrical Conductivity in a 3D Tetrahydroxyquinone-Based Metal-Organic Framework. J. Am. Chem. Soc. 2020, 142, 21243-21248.

17. (a) Karagiaridi, O.; Bury, W.; Tylianakis, E.; Sarjeant, A. A.; Hupp, J. T.; Farha, O. K. Opening Metal-Organic Frameworks Vol. 2: Inserting Longer Pillars into Pillared-Paddlewheel Structures through Solvent-Assisted Linker Exchange. Chemistry of Materials 2013, 25, 3499-3503. (b) Kapustin, E. A.; Lee, S.; Alshammari, A. S.; Yaghi, O. M. Molecular Retrofitting Adapts a Metal-Organic Framework to Extreme Pressure. ACS Cent. Sci 2017, 3, 662-667. (c) Schneider, C.; Bodesheim, D.; Keupp, J.; Schmid, R.; Kieslich, G. Retrofitting Metal-Organic Frameworks. Nat. Commun., 2019, 10, 4921. (d) Schneider, C.; Bodesheim, D.; Ehrenreich, M. G.; Crocellà, V.; Mink, J.; Fischer, R. A.; Butler, K. T.; Kieslich, G. Tuning the Negative Thermal Expansion Behavior of the Metal-Organic Framework $\mathrm{Cu}_{3} \mathrm{BTC}_{2}$ by Retrofitting. J. Am. Chem. Soc. 2019, 141, 1050410509.

18. Skorupskii, G.; Trump, B. A.; Kasel, T. W.; Brown, C. M.; Hendon, C. H.; Dincă, M. Efficient and tunable one-dimensional charge transport in layered lanthanide metal-organic frameworks. Nat. Chem. 2020, 12, 131-136.

19. (a)Yamashita, T.; Hayes, P. Analysis of XPS Spectra of $\mathrm{Fe}^{2+}$ and $\mathrm{Fe}^{3+}$ Ions in Oxide Materials. Appl. Surf. Sci 2008, 254, 2441 2449. (b) Conradie, J.; Erasmus, E. XPS Fe 2p Peaks from Iron Tris( $\beta$-diketonates): Electronic Effect of the $\beta$-diketonato Ligand. Polyhedron 2016, 119, 142-150.

20. Buchanan, R. M.; Kessel, S. L.; Downs, H. H.; Pierpont, C. G.; Hendrickson, D. N. Structural and Magnetic Properties of Tris(osemiquinone) Complexes of Iron(III) and Chromium(III). J. Am. Chem. Soc.1978, 100, 7894-7900.

21. Gütlich, P.; Gaspar, A. B.; Garcia, Y. Spin State Switching in Iron Coordination Compounds. Beilstein J. Org. Chem. 2013, 9, 342391.

22. Shaikh, N.; Goswami, S.; Panja, A.; Wang, X.-Y.; Gao, S.; Butcher, R. J.; Banerjee, P. New Route to the Mixed Valence Semiquinone-Catecholate Based Mononuclear Fe $\mathrm{Fe}^{\mathrm{III}}$ and Catecholate Based Dinuclear Mn ${ }^{\mathrm{III}}$ Complexes: First Experimental Evidence of Valence Tautomerism in an Iron Complex. Inorg. Chem. 2004, 43, 5908-5918.

23. (a) Dei, A.; Gatteschi, D.; Pardi, L.; Russo, U. Tetraoxolene Radical Stabilization by the Interaction with Transition-Metal Ions. Inorg. Chem. 1991, 30, 2589-2594. (b) Collins, K. A.; Saballos, R. J.; Fataftah, M. S.; Puggioni, D.; Rondinelli, J. M.; Freedman, D. E. Synthetic Investigation of Competing Magnetic Interactions in 2D Metal-Chloranilate Radical Frameworks. Chem. Sci. 2020, 11, 5922-5928.

24. Leonarska, A.; Kądziołka-Gaweł, M.; Szeremeta, A. Z.; Bujakiewicz-Korońska, R.; Kalvane, A.; Molak, A. Electric Relaxation and Mn 3+/Mn 4+ Charge Transfer in Fe-doped Bi 12 MnO 20BiMn 205 Structural Self-Composite. J. Mater. Sci. 2017, 52, 22222231.

25. Yong, X.; Shi, W.; Wu, G.; Goh, S. S.; Bai, S.; Xu, J.-W.; Wang, J.S.; Yang, S.-W. Tuning the Thermoelectric Performance of $\pi-\mathrm{d}$ Conjugated Nickel Coordination Polymers Through Metal-Ligand Frontier Molecular Orbital Alignment. J. Mater. Chem. A . 2018, 6, 19757-19766.

26. (a) Miller, J. S. Magnetically Ordered Molecule-Based Materials. Chem. Soc. Rev. 2011, 40, 3266-3296. (b) Park, J. G.; Collins, B. A.; Darago, L. E.; Runčevski, T.; Ziebel, M. E.; Aubrey, M. L.; Jiang, H. Z. H.; Velasquez, E.; Green, M. A.; Goodpaster, J. D.; Long, J. R. Magnetic Ordering Through Itinerant Ferromagnetism in a Metal-Organic Framework. Nat. Chem. 2021, 13, 594-598.

27. BbBanda, M. AC Susceptibility Studies of Phase Transitions and Magnetic Relaxation: Conventional, Molecular and Low-Dimensional Magnets. Acta Phys. Pol. A 2013, 124, 964-976.

28. (a) Chillal, S.; Thede, M.; Litterst, F. J.; Gvasaliya, S.; Shaplygina, T.; Lushnikov, S.; Zheludev, A. Microscopic Coexistence of Antiferromagnetic and Spin-Glass States. Phys. Rev. B 2013, 87, 220403. (b) Rojo, J. M.; Mesa, J. L.; Lezama, L.; Pizarro, J. L.; Arriortua, M. I.; Fernandez, J. R.; Barberis, G. E.; Rojo, T. Spin-glass Behavior in a Three-Dimensional Antiferromagnet Ordered Phase: Magnetic Structure of $\mathrm{Co}_{2}(\mathrm{OH})\left(\mathrm{PO}_{4}\right)$. Phys. Rev. $B$ 2002, 66, 094406.

29. A. J. Fatiadi and W. F. Sager. Org. Synth. 1962, 42, 66. DOI: 10.15227/orgsyn.042.0066.

30. (a) Lee, P. L.; Shu, D.; Ramanathan, M.; Preissner, C.; Wang, J.; Beno, M. A.; Von Dreele, R. B.; Ribaud, L.; Kurtz, C.; Antao, S. M.; Jiao, X.; Toby, B. H. A Twelve-Analyzer Detector System for High-Resolution Powder Diffraction. J. Synchrotron Rad. 2008, 15, 427-432. (b) Blanton, J. R.; Papoular, R. J.; Louër, D. PreDICT: a Graphical User Interface to the DICVOL14 Indexing Software Program for Powder Diffraction Data. Powder Diffr. 2019, 34, 233-241. (c) Louër, D. ; Boultif, A. Some Further Considerations in Powder Diffraction Pattern Indexing with the Dichotomy Method. Powder Diffr. 2014, 29, S7-S12.

31. Le Bail, A. Whole Powder Pattern Decomposition Methods And Applications: A Retrospection. Powder Diffr. 2005, 20, 316326. 
32. General Structure Analysis System (GSAS). (Report No. LAUR 86-748), Los Alamos National Laboratory, Los Alamos, NM. Larson, A. C. and Von Dreele, R. B. (2004).)

33. Favre-Nicolin, V. and Cerný, R. FOX, Free Objects For Crystallography: A Modular Approach to ab Initio Structure Determination From Powder Diffraction. J. Appl. Crystallogr. 2002, 35, 734743.

34. Ma, T.; Dong, B. X.; Grocke, G. L.; Strzalka, J.; Patel, S. N. Leveraging Sequential Doping of Semiconducting Polymers to Enable Functionally Graded Materials for Organic Thermoelectrics. Macromolecules 2020, 53, 2882-2892.

\section{TOC}

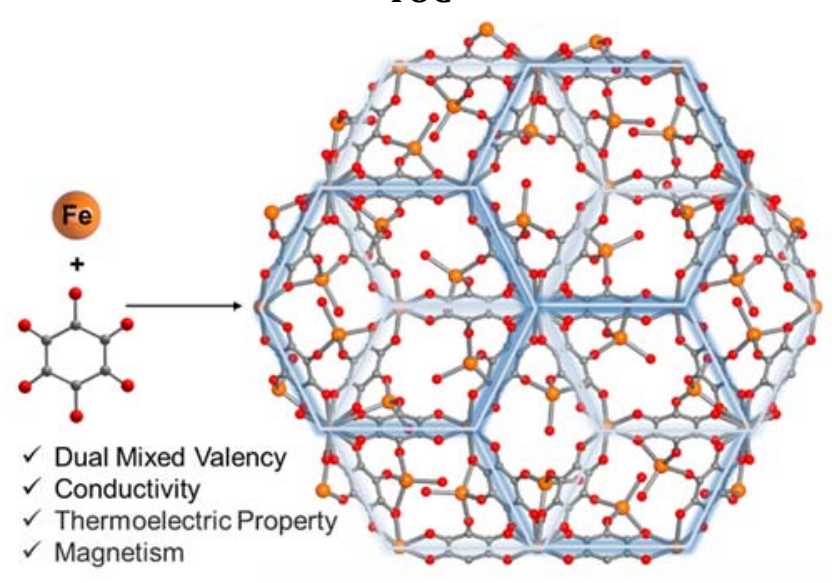

